\title{
NODE: a large-scale seismic risk prioritization tool for Italy based on nominal structural performance
}

\author{
Fabio Petruzzelli ${ }^{1} \cdot$ Iunio lervolino ${ }^{2}$ (D)
}

Received: 6 November 2020 / Accepted: 30 March 2021 / Published online: 18 April 2021

(c) The Author(s) 2021

\begin{abstract}
Prioritization of seismic risk mitigation at a large scale requires rough-input methodologies able to provide an expedited, yet conventional, assessment of the seismic risk corresponding to the portfolio of interest. In fact, an evaluation of seismic vulnerability at regional level by means of mechanics-based methods is generally only feasible for a fraction of the portfolio, selected according to prioritization criteria, due to the sheer volume of information and computational effort required. Therefore, conventional assessment of seismic risk via simple indices has been proposed in literature and in some guidelines, mainly based on the comparison of code requirements at the time of design and current seismic demand. These indices represent an attempt to define a relative seismic risk measure for a rapid ranking to identify the part of the portfolio that deserves further investigation. Although these risk metrics are based on strong assumptions, they have the advantage of only requiring easy-to-retrieve data, such as design year and location as the bare minimum, making them suitable for applications within the risk analysis industry. Moreover, they can take both hazard and vulnerability into account, albeit conventionally, and can be manipulated in order to account for exposure in terms of individual or societal risks. In the present study, the main assumptions, limitations, and possible evolutions of existing prioritization approaches to nominal risk are reviewed, with specific reference to the Italian case. Furthermore, this article presents the software NODE (available to interested readers), which enables the computation of location-specific code-based seismic performance demands, according to the Italian code and the evolution of seismic classification since 1909. Finally, this study intends to contribute to the ongoing debate on strategies for large-scale seismic assessment for building stock management purposes.
\end{abstract}

Keywords Portfolio management $\cdot$ Building code $\cdot$ Hazard $\cdot$ Vulnerability $\cdot$ Exposure

Iunio Iervolino

iunio.iervolino@unina.it

1 AXA XL Risk Consulting, corso Como 17, 20154 Milan, Italy

2 Dipartimento di Strutture per l'Ingegneria e l'Architettura, Università degli Studi di Napoli Federico II, via Claudio 21, 80125 Naples, Italy 


\section{Introduction}

The most critical aspect to date in seismic risk assessment of large-size structure portfolios, is the evaluation of structural vulnerability. Generally speaking, this evaluation can be approached via several methodologies, whose applicability is strongly dependent on portfolio size and level of information attainable about the structures that it is made of (JRC 2013). At a large scale, when hundreds or thousands of structures are involved, an explicit assessment of vulnerability by means of mechanics-based methods is generally unfeasible, due to the size of the population of buildings under investigation and the inter-building variability in terms of structural system, building materials, detailing, reference building code, construction practice and aging conditions. Thus, it emerges a requirement for the development of simplified procedures.

Several methods have been developed in the literature for the evaluation of vulnerability at a large scale. They can be generally classified into: (1) observational, (2) expert-judgment-based, (3) mechanics-based methods (Calvi et al. 2006). ${ }^{1}$ Observational approaches for large-scale vulnerability assessment are usually based on the definition of a relationship between building typology and observed damage through the statistical analysis of post-earthquake damage surveys. Data retrieved from this kind of analysis can be used to obtain Damage Probability Matrices (DPM) (e.g., Braga et al. 1982 and 1985), as well as observational fragility curves for different structural typologies (e.g., Rossetto and Elnashai 2003; Rota et al. 2008). The accuracy of this approach is affected by the availability of damage data for different building classes, soil conditions and recorded seismic intensity at the sites where damage is observed.

In order to overcome the inherent difficulty in retrieving data, expert judgment-based methods have been developed in the literature, based on the identification of pre-defined structural vulnerability indicators within the building stock, resulting in expert-based DPMs (ATC 1985) or score assessment procedures (ATC 2004). Critical aspects of such approaches are the definition of the relative importance of the adopted indicators and their use to get quantitative estimates of the seismic risk. The works by Angeletti et al. (1988), by the Gruppo Nazionale Difesa dai Terremoti (GNDT) (Benedetti and Petrini 1984) and Di Pasquale et al. (2005), represent the main reference examples for the Italian context.

Structural-mechanics-based methods for seismic risk assessment are aimed at the evaluation of the seismic vulnerability of a portfolio of buildings through mechanical modelling; e.g., Lagomarsino and Giovinazzi (2006). Generally, these take a structure-specific modelling approach at the class level, that is, a meso-scale (e.g., Calvi 1999; Iervolino et al. 2007). The difficulties of adopting this approach at a regional scale is that they need to define homogeneous building classes, whose vulnerability is assessed by analyzing a number of numerical models, which somehow account for both intra- and inter-structure (within the class) uncertainties. This approach may still require an amount of information corresponding to, at least, visual inspection of all buildings in the portfolio and seems more suitable for analyzing mid-size (e.g., district-level) populations of structures.

Regardless of the approach chosen for vulnerability assessment, the limited amount of resources available for investigating the building stock, assessing the risk and reducing it by implementing mitigation strategies, forced stakeholders to approach risk-management of large-size building portfolios in a multi-step manner. For example, American (ATC

${ }^{1}$ It is to mention that hybrid approaches also exist; e.g., (Kappos et al. 2006). 
1978) and New Zealand (NZSEE 2003) guidelines, include criteria for defining acceptable risk levels and procedures for ranking priorities. With specific reference to the Italian context, one could recall the work by Di Pasquale et al. (2001), Goretti and Di Pasquale (2004) and Grant et al. (2007), for the definition of retrofit priorities in the portfolio of Italian school buildings. Generally, these procedures include a first phase for screening the building population and selecting the fraction of structures, which is likely to deserve further investigation. The second step is a more refined analysis, which may involve the assessment of structure-specific vulnerability.

Structural typology, geometry, location, and building age, is the kind of information likely to be available at the beginning of the analysis of large populations of structures. Therefore, comparing seismic performance requirements at the time of design with current code requirements, for a similar structure at the same site, may prove useful for risk mitigation prioritization, although it may be insufficient for the development or selection of a specific vulnerability model. ${ }^{2}$ Assuming perfect code compliance and other hypotheses (which may be strong, as discussed in the following), several indices based on the gap between design seismic demand, according to the current seismic code and the one at the time of construction, ${ }^{3}$ have been proposed (NZSEE 2003; Grant et al. 2007; Crowley et al. 2008; Gattesco et al. 2011). These can provide a rough measure of the nominal deficit of structural seismic performance and, accordingly, a relative and conventional, yet quantitative, measure of actual seismic risk, if this approach is consistently applied within the investigated population. In fact, such indices conventionally account for both vulnerability and hazard and may be extended to also include socio-economic exposure. The age of the engineered building stock in Italy and the evolution of design principles and seismic actions in national codes, render this kind of approach worthy of further investigation.

In the presented study, a brief review of the evolution of design provisions and seismic hazard classification in Italy is given first. Then, the scientific mainstream of nominal risk indices is discussed with respect to underlying assumptions, critical issues, limitations, and implications. A software, namely NODE-NOminal DEficit—v.1.1 beta, enabling a rapid evaluation of the horizontal performance requirements (due to earthquake and wind) for Italian constructions at any site between 1909 and today, is introduced. It allows to assess location-specific code-based design standards, thus, to automatically compute nominal risk proxies for large populations of buildings, which may contribute to nation-scale risk maps (Crowley et al. 2009). An illustrative application of NODE closes the study.

\section{Chronicle of italian seismic structural requirements}

Italy is generally considered to be a country of relatively moderate seismicity, yet high seismic risk. In fact, this has been repeatedly demonstrated by the large consequences of recent moderate magnitude earthquakes; e.g., L’Aquila, 2009 (moment magnitude, M, 6.3) Emilia, 2012 (M 6.1), Amatrice 2016 (M 6.0). It is commonly acknowledged that one of the most important sources of vulnerability can be attributed to the lack of seismic provisions in design or compliance with obsolete code provisions, that inherently underestimate

\footnotetext{
${ }^{2}$ Except for special cases of highly standardized structures such as oil storage steel tanks (Iervolino et al. 2004).

3 It is expected that the current seismic demand is larger than any previously enforced, this is also due to the increasing trend of hazard estimates; see Bommer and Abrahamson (2006) for a discussion.
} 
the design actions (i.e., hazard) with respect to contemporary standards. Figure 1 reports the design age for the Italian building stock, according to 2001 census data (ISTAT 2001). It is possible to observe that, except for masonry non-engineered structures, a large part of the structures was designed between the ' $60 \mathrm{~s}$ and ' $70 \mathrm{~s}$, a period in which, as will be discussed in the following, only a fraction of the Italian territory, ranging between $15 \%$ and $35 \%$, was considered to be seismically prone. For these reasons, the knowledge of the evolution of structural seismic provisions in Italy can be indicative, at least in a preliminary prioritization scheme, of the actual structural vulnerability.

\subsection{Early history}

Seismic regulatory codes in Italy have undergone a significant number of changes that, until very recently, typically went into effect in the aftermath of catastrophic seismic events. In this section, a few fundamental steps are reviewed, while the reader should refer to Di Pasquale et al. (1999a and b), where most of this information is to be found, for a much more comprehensive and informative review.

The Royal Decree (Regio Decreto, or R.D.) no.193 of 04/18/1909, came into effect after the Messina Strait earthquake of 1908 (M 7.1), and is usually referred to as the first documented national Italian seismic building code. It contained instructions to be applied at the most heavily stricken areas, which were also defined as seismic zones. In fact, in order to control the seismic vulnerability of new constructions, some limitations about building height and other provisions for different structural typologies were given. Although no quantification of horizontal design forces was included, an expert panel recommended to check the building's stability under horizontal forces of the order of magnitude of $8 \%$ with respect to the weight (i.e., the so-called seismic coefficient was 0.08 ).

The first explicit provision regarding the value of the horizontal seismic base shear was introduced in 1915 with the royal decree law (Regio Decreto Legge or R.D.L.) no. 573 of 04/29/1915, after the Avezzano earthquake in the Abruzzo region (M 7). It provided seismic forces equal to $1 / 8$ and $1 / 6$ of story weight, for the first and upper levels, respectively. Moreover, the seismic weight, $W$, was defined as the sum of dead loads plus the quasipermanent live loads, increased by $50 \%$, to take into account the vertical seismic action.

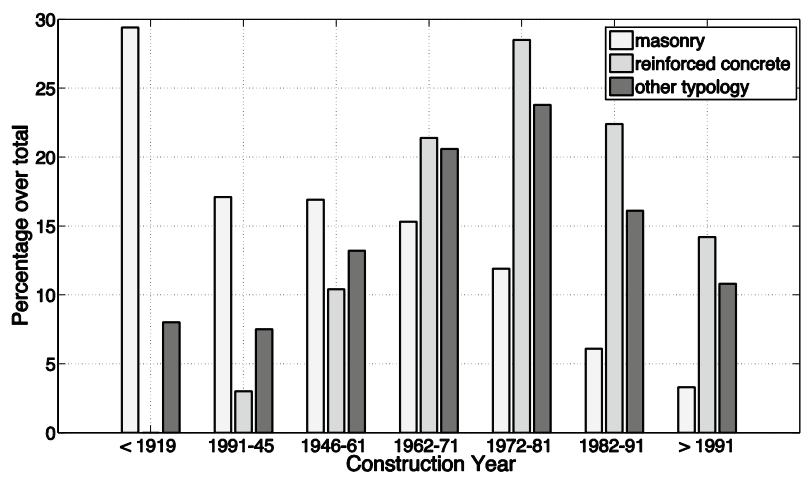

Fig. 1 Italian building stock in terms of year of construction, according to 2001 Istituto Nazionale di Statistica (ISTAT) census data 
According to R.D.L. no. 431 of 03/13/1927 a lower level of seismic base shear and less restrictive structural provisions were introduced for sites considered to be of moderate seismicity. In those zones, belonging to the so-called second category or category II, the seismic action was equal to $1 / 10$ of building weight at each level, while seismic actions for buildings located in highly hazardous sites (first category or category I) remained unchanged. The code also prescribed that the seismic weight to be considered in category II should be equal to the sum of dead loads plus the quasi-permanent live loads, increased by $33 \%$, to take into account the vertical seismic action.

The R.D.L no. 640 of 03/25/1935 reduced the horizontal seismic force to the 10 and 7 of the seismic weight in category I and II, respectively. Furthermore, seismic weight was reduced to the 40 and $25 \%$, respectively in category I and II, of dead and live loads (the latter limited to $1 / 3$ of its maximum value). The assumption of a constant distribution of forces along building height independently from the seismic category, established in 1935 (for all seismic categories) and substantially unchanged up to 1975, represents another step backwards with respect to the provisions of previous codes. Moreover, in 1937 (R.D.L. no. 2105 of $11 / 22 / 1937$ ) the seismic coefficient for category II was further reduced to 0.05 .

The 1962 code (law no. 1684 of 11/25/1962) did not bring substantial innovation to seismic design; however, horizontal seismic forces were assumed equal to 10 and $7 \%$ of seismic weight, depending on the seismic zone.

\subsection{Modern era}

A major step in the evolution of seismic codes in Italy was Law no. 64 of 02/02/1974, which gave the administrative framework of seismic regulations in Italy, entrusting the periodical updating of technical provisions to the government. The ministry decree (Decreto Ministeriale or D.M.) no. 40 of 03/03/1975 was the first code issued in accordance to the previous law and introduced significant changes in Italian seismic provisions. It introduced the response spectrum and dynamic or static analyses were given as design options. The base shear, $V_{b}$, was given as a function of the seismic zonation, soil type, structural system, structural oscillation period, and seismic weight:

$$
V_{b}=C \cdot R \cdot \varepsilon \cdot \beta \cdot W .
$$

In the previous equation, $W$ is the seismic weight of the building (defined as the sum of dead loads and a portion of live loads equal to $1 / 3,1 / 2$ and 1 , respectively for ordinary, crowded and overcrowded buildings), $\varepsilon$ accounts for soil compressibility ( $\varepsilon$ was equal to 1.00 in the case of stiff soil and 1.30 in the case of deformable soil), $\beta$ is a so-called structural coefficient accounting for the possible presence of structural walls ( $\beta$ was equal to 1.20 in the case of structural walls and 1.00 in the other cases) and $C$ is the seismic coefficient ( 0.10 and 0.07 for first and second category, respectively). The $R$ term in Eq. (1), defined a sort of design (response) spectrum shape. Its expression, substantially unchanged until 2003, was defined as follows:

$$
\begin{cases}R=1 & T_{1} \leq 0.8 s \\ R=0.862 \cdot T_{1}^{-2 / 3} & T_{1}>0.8 s\end{cases}
$$

where $T_{1}$ represented the structural fundamental period. Finally, the seismic force defined according to Eq. (1) was distributed proportionally to the story heights. Despite the step forward accomplished through the introduction of the response spectrum, no indications 
were given about how the reference seismic action had been defined and how it was transformed into a design spectrum.

After the Irpinia earthquake in 1980 (M 6.9), a third seismic category was introduced (D.M. no. 515 of 06/03/1981), corresponding to a $C$ coefficient, in Eq. (1), equal to 0.04. A further evolution of Italian regulatory provisions saw the definition of an importance factor (I) in 1984 (D.M. 06/19/1984), in order to amplify the design base shear provided by Eq. (1). That factor was set to 1.2 in the case of relevant buildings and 1.4 for primary civil protection buildings.

Up to 1996 the only design approach was based on admissible stress, that is, conventional elastic analysis at the material level. The D.M. of 01/16/1996 introduced limit state design. However, the admissible stress approach, by virtue of being much more familiar to practitioners, was still allowed, so that the limit state design was largely defunct in practice. Moreover, the instruction document related to the 1996 code (Circolare M.LL.PP. no. 65 of 04/10/1997), contained the first indications in the direction of capacity design; e.g., detailing in nodal zones to improve local and global ductility.

\subsection{State-of-the-art and current codes}

The 2003 seismic code (O.P.C.M. 3274 2003), and its subsequent modifications (O.P.C.M. 3431 2005), represented the most significant change in Italian seismic provisions over thirty years. In fact, Eurocode 8 or EC8 (CEN 2004) approach was acknowledged, and a fourth seismic zone was introduced. An elastic response spectrum with a fixed shape (depending on local geology), anchored to a conventional peak ground acceleration (PGA), was enforced. Reference PGA values for the four zones were $0.35 \mathrm{~g}, 0.25 \mathrm{~g}, 0.15$ and $0.05 \mathrm{~g}$ for zones from 1 to 4, respectively. Each site fell in one of the four categories depending on the PGA, on stiff soil, with an exceedance return period of 475 years, evaluated by means of probabilistic seismic hazard analysis. The elastic response spectrum had to be modified as a function of the behavior factor, $q$, to get the (inelastic) design spectrum required by some analysis methods. This code also enforced, for the first time, capacity design principles.

For structures with a fundamental period larger than the one corresponding to the end of the constant acceleration branch of the design spectrum, the design base shear was defined as in Eq. (3), where $\lambda$ was a coefficient equal to 0.85 for static analysis, $S_{a}\left(T_{1}\right)$ was the elastic spectral acceleration, $q$ was the behavior factor and $g$ the gravity acceleration:

$$
V_{b}=S_{a}\left(T_{1}\right) \cdot W \cdot \lambda /(q \cdot g) .
$$

However, despite its major advances, this code release was compulsory only for buildings of strategic importance, and practitioners were still allowed to use the 1996 code.

The semi-last regulation (D.M. 2008), in the following referred to as new Italian building code or NIBC08, finally enforced performance-based design criteria (without alternative options for strategic and non-strategic buildings), after L'Aquila earthquake in 2009. A major novelty of the NIBC08 consisted in the fact that design seismic hazard was defined completely on probabilistic basis as a function of geographic coordinates of the construction site, and no longer on a municipality basis (see the following section). Regarding ordinary buildings in the sites located in zone 4, it allowed the use of the admissible stress methodology included in the DM of 16th January 1996. In 2018 a revision of the NIBC08 (NIBC18) was released (D.M. 2018), without substantial changes in the definition of elastic seismic actions on structures. (In the following, NIBC will be used when no distinction is necessary between NIBC08 and NIBC18.) 
As an example, in summary, the evolution of code-based seismic actions throughout the years for a downtown L'Aquila site (Lat: 42.36, Lon: 13.41) is reported in Fig. 2, in terms of seismic coefficient or acceleration response spectrum, if applicable. Note that, since 2003 , the spectrum is elastic with $5 \%$ damping. The latter has to be reduced by the aforementioned behavior factor to account for inelastic deformations.

\section{Evolution of seismic classification (design hazard) in Italy}

Since 1909, the complex task of mitigating the seismic risk in Italy was entrusted, on one hand, to seismic building codes and, on the other hand, to seismic classification regulations, defining which areas of the Italian territory are to be considered as earthquake prone and how much. In several cases, up until the '70s, a region was considered to be seismically prone only after the occurrence of a seismic event. This aspect clearly emerges from Fig. 3, where a few steps in the evolution of seismic classification from 1909 to 1962 are shown, factually reflecting the distribution of observed earthquakes through the territory.

A peculiar, yet relevant, aspect is that, between 1916 and 1936 or 1937 and 1962, several municipalities were de-classified, that is, taken from being classified as seismically prone zones to non-seismically-prone.

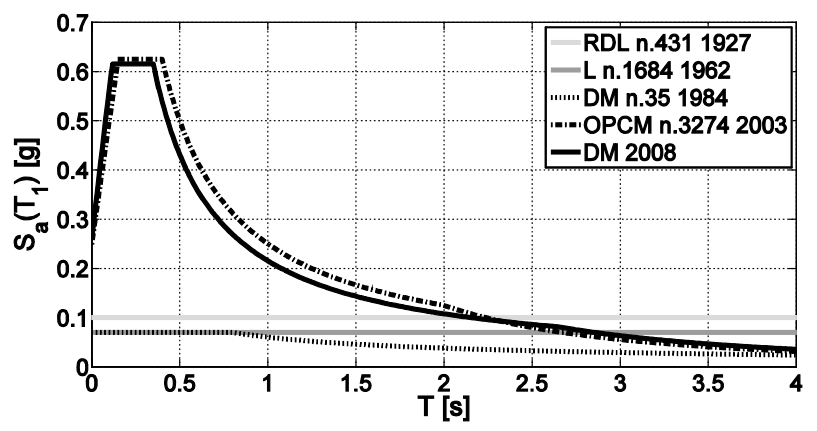

Fig. 2 Reference seismic demand evolution for L'Aquila site (Lat: 42.36, Lon: 13.41)
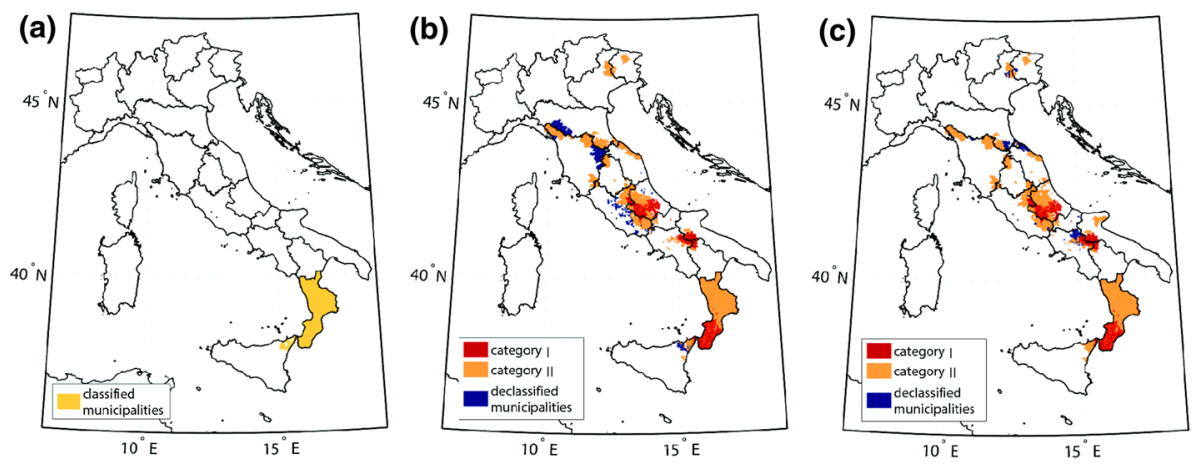

Fig. 3 Italian seismicity map after year 1909 (a), 1937 (b), 1962 (c) 
The Law No. 1684 of 11/25/1962 claimed that seismic codes should be applied to municipalities subject to intense seismic activity but until the early ' $80 \mathrm{~s}$ this prescription remained substantially void. In 1974 (Law no.64 of 02/02/1974) the need to classify the territory on the basis of proven technical reasons was reaffirmed, and in 1979 macroseismic intensity maps were used as a basis for the identification of seismic zones, defined reflecting municipal borders (Di Pasquale et al. 1999a). This led to the issuing of several decrees aimed at the territorial seismic classification between 1979 and 1984 (Di Pasquale et al. 1999b), so that, at the end of 1984 , the $37 \%$ of municipalities and the $45 \%$ of the Italian territory was considered to deserve seismic design.

The earthquake in San Giuliano di Puglia (M 5.8), 2002, dramatically brought to attention the lack of updates of the seismic classification of the Italian territory, which had remained the same since 1984. During the post-earthquake emergency, the O.P.C.M. 3274 (2003) updated the definition of seismic zones introducing a fourth one, characterized by lower seismic hazard, replacing the unclassified regions in previous zonations. Therefore, a minimal level of seismic design was ensured for the entire country, although individual regions in zone 4 might choose not to adopt the new seismic classification.

In the following years, thanks to the work of the Istituto Nazionale di Geofisica e Vulcanologia (INGV) (Stucchi et al. 2011), a probabilistic seismic hazard analysis was performed for several spectral ordinates at each point of a fine grid, covering the whole Italian territory (except the Sardinia region). Moreover, design elastic response spectra were defined starting from uniform hazard spectra, computed as a function of the geographical coordinates of the site.

In Fig. 4 the most relevant changes in the Italian seismic classification from 1984 are illustrated. Table 1, summarizes the most relevant changes in base shear provisions (see Sect. 2) and territorial classification between 1909 and 2008 (the latter representing current situation).

\section{Nominal seismic risk indices}

The significant evolution of seismic codes and the improved estimates of seismic hazard over the years, make the reference (i.e., at the time of design) seismic action for the existing building stock heterogeneous and generally lower than the current one, which may be
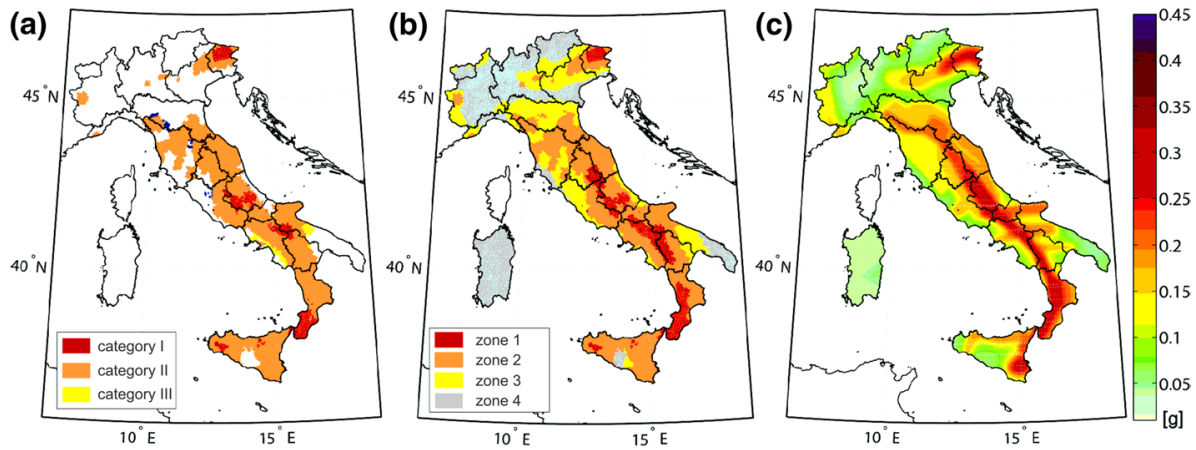

Fig. 4 Italian seismicity map after year 1984 (a), after 2003 (b) and NIBC08-18 map of PGA with 475 years exceedance return period $(\mathbf{c})$ 


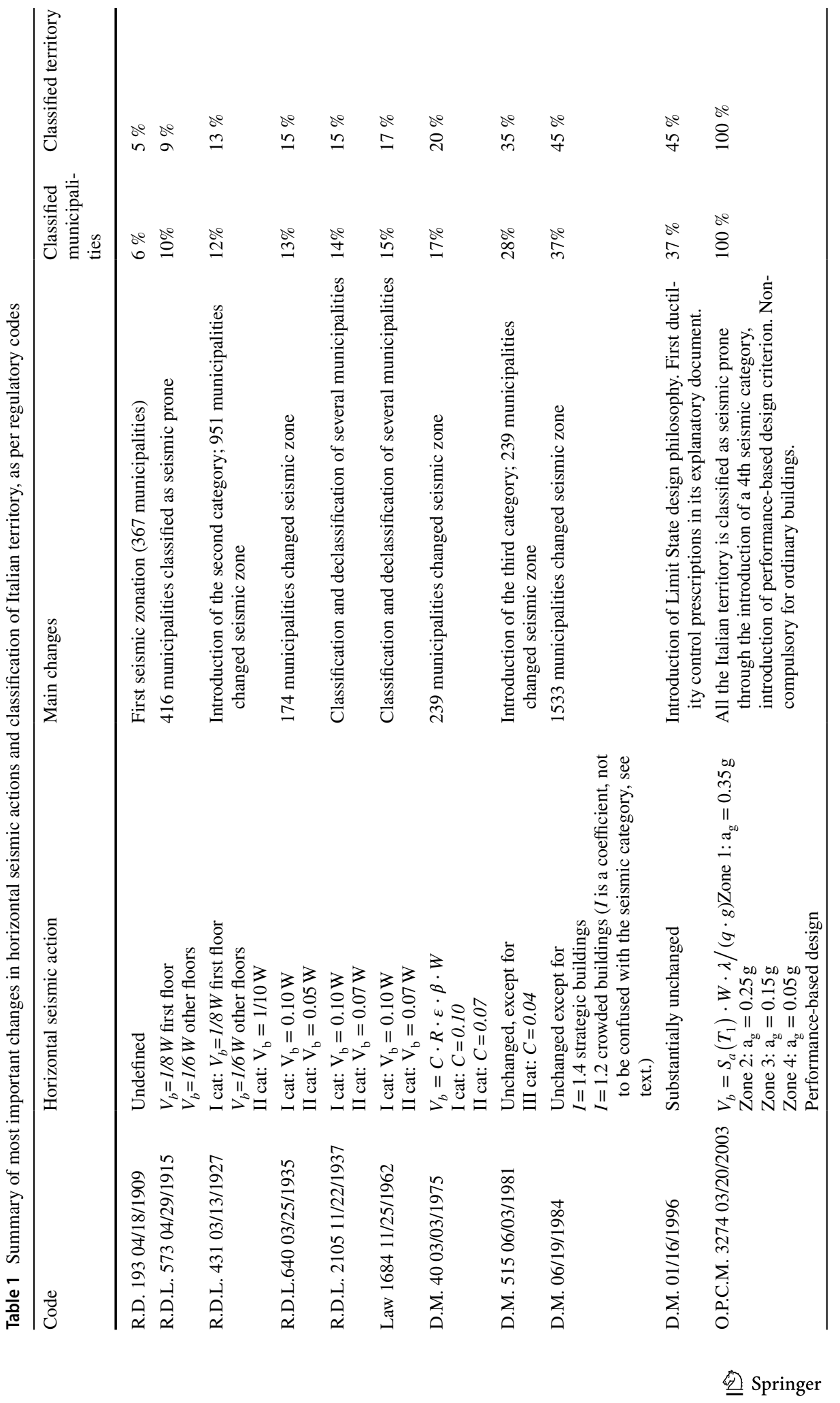




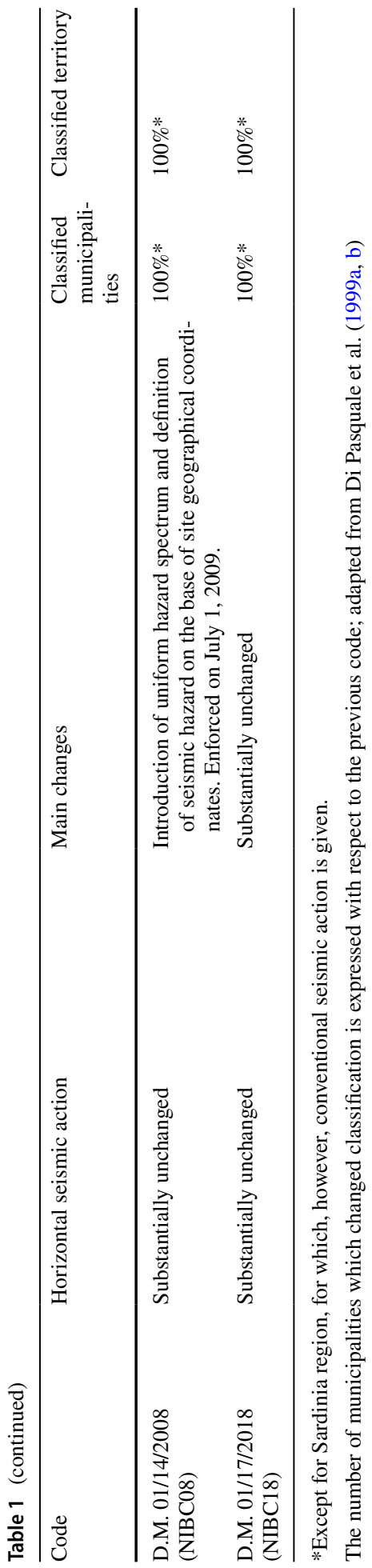

Springer 
considered to reflect the code's adaptation of state-of-the-art earthquake engineering. This suggests that it may be useful, in the Italian context, to investigate risk metrics based on such information. Indeed, in this section, some of the indices available in literature for large-scale prioritization are discussed. Due to their nominal nature, these indices may provide relative measures of risk for the definition of management/mitigation priorities if consistently applicable to the whole portfolio. Their computation can be generally performed as a desk study (i.e., without on-site inspection) or on the basis of simple and easy-toretrieve data. This evaluation has, most likely, to be followed by further analyses to get risk metrics via structural seismic assessment (i.e., the annual failure rate or the annual expected loss).

Among the risk indices available in literature, only those expressing vulnerability and hazard through quantitative measures will be considered in the following. These indices share the same assumption that the gap between the actual seismic demand and the seismic demand at the time of the design can be considered as an indicator of structural performance deficit (see Sect. 6 for a discussion of assumptions and limitations).

\subsection{NZSEE (2003)}

The first approach that employed a quantitative seismic deficit index was the one included in the New Zealand guidelines for the Assessment and Improvement of the Seismic performance of Buildings in Earthquakes (NZSEE 2003). This approach moves from an initial evaluation procedure (IEP), consisting of a screening of the portfolio, performed in order to select structures (top ranking) to be analyzed in more detail by mechanical modeling. In this phase, a so-called baseline percent new building standard index is computed as the product of six terms, providing the expected building strength, in the hypothesis of no structural deficiencies. It is obtained as a function of the structural typology and the building age and reflecting the requirements of the code enforced at the time of design. Such coefficients are intended, therefore, to conventionally quantify the performance of the building with respect to modern requirements, assuming the compliance with code provisions that were in effect at the time it was built.

The aforementioned index is further modified in order to conventionally take into account structural weaknesses, such as vertical and plan irregularities and the presence of short columns, thus providing the so-called structural performance score (SPS). The SPS index is structured in a form similar to a capacity to demand ratio and it is expressed as a percentage of the seismic performance required for a new building. In fact, if SPS is lower than 1 , the risk of the considered existing building is larger than the one of a new construction, if SPS is lower than 0.67 the structure is potentially at risk, if SPS is lower than 0.33 the structure is potentially vulnerable to earthquakes. In the last two cases further analyses are needed, performed after collecting building characteristics and details.

\subsection{Grant et al. (2007)}

Grant et al. (2006 and 2007) proposed a prioritization scheme for seismic retrofit of school buildings in Italy, providing timescales for retrofitting or demolition. Due to the large amount of structures to be investigated (approximately 60,000), the procedure comprises multiple levels of assessment with an increasing level of detail. Each level aims at reducing the size of the building inventory under investigation for the subsequent step. The first level 
of the procedure is similar to the IEP of NZSEE (2003) and consists in the computation of the nominal risk index expressed by Eq. (4):

$$
P G A_{\text {deficit }}=P G A_{D}-P G A_{C} .
$$

In the previous formulation, $P G A_{D}$ is the reference seismic hazard, that is the seismic demand provided by the most up-to-date hazard study available. At the time of the work by Grant et al. (2007) this was the O.P.C.M. 3274 (2003).

The $P G A_{C}$ term represents the seismic capacity of the structure and is computed, under the hypothesis of uniform and consistent code compliance, as the demand defined by the code enforced when the building was designed, rendered somewhat comparable to the reference demand. In fact, since PGA values have only been explicitly defined since 2003, for previous codes the authors define a so-called effective PGA, that is calculated under two assumptions. First, the authors assume that the fundamental period of the building, $T_{1}$, is relatively short, so that it can be considered to lie into the constant acceleration range of the design elastic response spectrum; second, they consider the design performance to be inelastic. Moreover, even if the authors recognize the ductility to vary for different structural systems and different codes through the years, they assume a unique building typology (unreinforced masonry, by a cautionary approach) and a constant behavior factor equal to 3.6 .

Under the previous assumptions, the effective PGA can be computed as in Eq. (5), for a structure designed after 1975 (i.e., after the introduction of the design response spectrum):

$$
P G A_{C}=S_{e, C}\left(T_{1}\right) /\left(\frac{S_{e, D}\left(T_{1}\right) / q}{P G A_{D}}\right) .
$$

In the previous Equation, $S_{e, D}\left(T_{1}\right) / q$ is the reference design (inelastic) spectral acceleration, $P G A_{D}$ is the reference PGA and $S_{e, C}\left(T_{1}\right)$ is the spectral acceleration provided by the code enforced at the time of the design. The latter is, for post-1975 buildings, $S_{e, C}\left(T_{1}\right)=C \cdot R \cdot \varepsilon \cdot \beta$; see Eq. (1). Conversely, in the case of structures designed before 1975 , it is the seismic coefficient.

As shown in Fig. 5 with reference to a structure designed according to the 1962 Code, applying Eq. (5) is equivalent to fitting the spectral shape provided by the reference code to the seismic demand at the time of design (the latter expressed either in terms of spectral ordinate or seismic coefficient, depending on the time of design), considered to be a constant, inelastic, spectral ordinate.

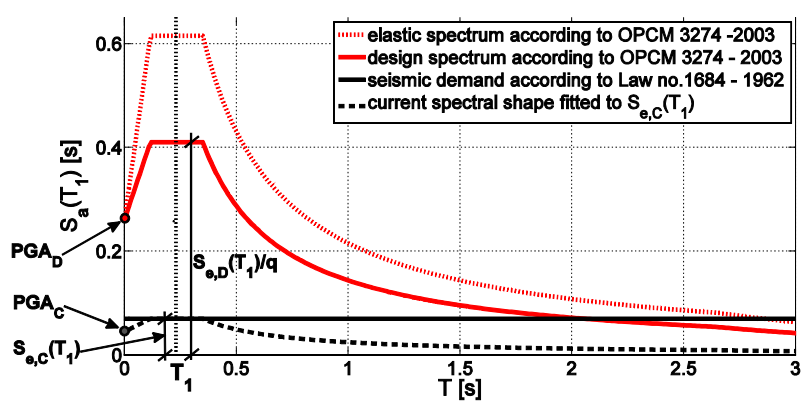

Fig. 5 Definition of the effective PGA (PGA $)$ according to Grant et al. (2007) 
Moreover, in consideration of the particular use of the case-study portfolio (schools) they assume an importance factor equal to 1.2 for all post-1984 constructions. This factor, amplifying the $S_{e, C}\left(T_{1}\right)$ term in Eq. (5), results in an increase of the effective design PGA and, therefore, a decrease of $P G A_{\text {deficit }}$ for all structures designed after 1984. It is also assumed that all the buildings are built on stiff soil, so that site effects can be neglected, and that live loads are negligible with respect to dead loads.

In the case of buildings designed before the introduction of any seismic design requirement, the authors assume a $P G A_{C}$ equal to zero, neglecting the contribution to lateral strength due to gravity design or wind design. Despite of this, the authors recognize the possibility of assuming a minimum value of $P G A_{C}$ in the case of pre-code buildings; i.e., those for which no seismic design was performed.

As a result of the first screening phase, only a portion of structures with the largest PGA deficit passes to the second phase, which is based on the evaluation of some semi-quantitative vulnerability as per GNDT procedures (Benedetti and Petrini 1984; Angeletti et al. 1988). Such procedures provide the collapse PGA value as a function of a vulnerability index based on expert judgement and field surveys.

Considering the approximate hazard curve from Eurocode 8, according to which the relationship between the logarithm of PGA and the logarithm of annual rate of exceedance may be approximated by a line with $-k$ slope (at least in the range of return periods of engineering interest), the hazard curve for the site, in terms of PGA, may be defined by the value of PGA corresponding to a given annual rate of exceedance, and the slope of the line interpolating passing from the reference point (Grases et al. 1992).

This collapse PGA computed by means of GNDT model is used to define the $P G A_{C}$ term in Eq. (6), expressing the collapse probability. In fact, if the vulnerability index and the GNDT model parameters are considered to be fully deterministic, then a PGA value larger than $P G A_{C}$ will cause structural failure. Under this assumption the annual frequency of collapse can be expressed as the annual frequency of exceedance of a PGA level equal to $P G A_{C}$ (Grant et al. 2006). Assuming that the annual probability of exceedance of $P G A_{C}$ is approximately equal to the annual rate of exceedance, the annual probability of collapse $P$ [collapse] can be given by the following expression:

$$
P[\text { collapse }]=P\left[P G A_{D}\right] \cdot\left(\frac{P G A_{D}}{P G A_{C}}\right)^{k} .
$$

Finally, it can be noted that in the approach proposed by Grant and his co-workers, no close relationship seems to exist between the nominal index computed in the first phase and the semi-quantitative one employed in the second. Therefore, the main function of the first conventional measure seems to be restricted to the reduction of the portfolio size.

The strong assumptions regarding fundamental period, soil conditions, and behavior factor, may be justified by the homogeneity use of the building stock and the necessity of limiting the amount of input data. In fact, under the previous assumptions the first screening phase do not require inspection and specific studies of the buildings of the portfolio, but only the knowledge of building's location and design year, while the second ranking employs expert judgment-based indices already available from national research programs (e.g., SERGISAI 1997; Grimaz et al. 2016). 


\subsection{Crowley et al. (2008)}

Crowley et al. (2008) proposed a modification to the approach by Grant et al. (2007) and applied the procedure to the school buildings of two Italian regions. First, in order to make the two steps of the procedure described in the previous section comparable, the risk rating computed in the first step was calculated as per Eq. (7), defining the $P G A_{C}$ term as the design PGA, based on year of construction and location. A minimum design PGA of $0.06 \mathrm{~g}$ was assumed for buildings designed in non-seismic zones:

$$
\text { Risk Index }_{P G A}=\left(\frac{P G A_{D}}{P G A_{C}}\right)^{k} \text {. }
$$

The authors noted that employing the above-defined index in the first screening procedure, led to measures of seismic risk coarsely related with those obtained in the second step, by means of Eq. (6), when the $P G A_{C}$ value is taken from the GNDT approach. Therefore, a new risk rating index was proposed, expressed in terms of spectral ordinates, as reported in Eq. (8):

$$
\operatorname{Risk} \operatorname{Index}_{S_{a}(T)}=\left(\frac{S_{a}(T)_{D}}{S_{a}(T)_{C}}\right)^{k} .
$$

This risk index proved (Crowley et al. 2008) to be better correlated with the one computed at the second step of the Grant et al. (2007) approach in Eq. (6).

In the previous equations the absolute value of the slope, $k$, of the hazard curve at the return period of interest, is the one for the spectral ordinate corresponding to the period of oscillation of the building, calculated as reported in Borzi et al. (2008). For masonry buildings, the spectral ordinate corresponding to the capacity, $S_{a}(T)_{C}$, was obtained directly from the GNDT second level forms (Benedetti and Petrini 1984), while for reinforced concrete structures it was defined as the seismic design provision in force at the time of construction, multiplied by an overstrength factor. The authors refer to a minimum overstrength factor of 3.5. Moreover, the authors assume, for building designed according to the current code, an inelastic strength equal to the elastic one, due to the structural overstrength of new buildings (Mwafy and Elnashai 2002).

\section{Alternative deficit measures based on design strength}

Based on the rationales of the indices above, if the information for the structures in the portfolio is such that a more refined estimate of the design base shear is possible, an alternative measure of the nominal deficit (NODE) can be defined (Iervolino and Petruzzelli 2011). This is described in this section, while assumptions and limitations are discussed in the next section. The aim is to quantify a difference proportional to the base shears assumed for seismic design according to the current code and that actually enforced at the time of the design.

Two equivalent options are available: (1) to compare the inelastic design performance of the structure (assuming that the one assumed at the time of design can represent such a behavior for the existing structure, to follow); (2) to compare the elastic demand at the time of construction with the current demand retrieved from elastic-response seismic hazard. 
In the first case, the base shear for a new construction for which static analysis may be applied, $V_{b, \text { new }}$, may be computed as in Eq. (9):

$$
V_{b, \text { new }}=\frac{S_{e, D}\left(T_{1, \text { new }}\right)}{q} \cdot m,
$$

in which $S_{e, D}\left(T_{1, \text { new }}\right)$ is the elastic seismic demand in terms of elastic spectral acceleration at the fundamental period of the structure, as defined by current seismic code (i.e., NIBC), $q$ allows to transform the elastic acceleration to the design, inelastic, one and its definition is a critical issue (see Sect. 6). ${ }^{4}$

It is worth noting that, in the definition of the current base shear, the $\lambda$ coefficient accounting for the mass participation to the first mode of vibration is set to one; see Eq. (3). On one hand, this assumption is motivated by the relative nature of the nominal deficit index (the $\lambda$ coefficient would consistently modify the current seismic demand term for all the structures of the portfolio); on the other hand, it should be noted that such an index is suitable for structures that could be analyzed with a static equivalent analysis (i.e., having a dynamic behavior which can be reduced, with a good approximation, to the first mode of vibration).

Similarly, the nominal capacity, in terms of base shear, $V_{b, o l d}$, can be expressed as in Eq. (10):

$$
V_{b, \text { old }}=S_{d, C}\left(T_{1, \text { old }}\right) \cdot m,
$$

where $S_{d, C}\left(T_{1, \text { old }}\right)$ is the spectral ordinate determined on the basis of the seismic action at the time of design (considered to be related to the inelastic demand). In the case of a structure designed after 1975, it is the design spectral acceleration at the fundamental period of the structure; otherwise, it is the seismic coefficient (see Sect. 2).

In the previous equations the $m$ term represents the total mass of the building (the weight of the structure, $W$, divided by the acceleration of gravity, $g$ ), obtained by only considering dead loads; this is to say that the assumption of negligible live loads with respect to permanent ones is made. This allows to simplify the assessment of nominal seismic weight, and thus neglect its variability over the years and building codes. In this manner, it is possible to express the $N O D E$ index in the following equivalent form, which is more hazard-friendly; Eq. (11):

$$
N O D E_{S_{a, d}(T)}=\frac{S_{e, D}\left(T_{1, \text { new }}\right)}{q}-S_{d, C}\left(T_{1, \text { old }}\right) .
$$

In an equivalent manner, it may be considered that the design base shear at the time of design was an elastic one with a known behavior factor, in such a case NODE may assume the form of Eq. (12), which may be referred to as an elastic NODE index: ${ }^{5}$

$$
N O D E_{S_{a, e}(T)}=S_{e, D}\left(T_{1, \text { new }}\right)-S_{d, C}\left(T_{1, \text { old }}\right) \cdot q .
$$

\footnotetext{
${ }^{4}$ For new construction the actual design base shear is further reduced with respect to the elastic demand because of the partial safety factors assumed for materials; this issue is disregarded herein.

5 The plausibility of this assumption is also remarked by the nature of $\beta$ coefficient in Eq. (1), which can be considered a simplified way for considering the inelastic behaviour of different structural systems (frame structures and shear wall structures) and, therefore, sort of inverse behaviour factor (Ricci et al. 2011).
} 
The two indices, beyond their apparent differences, share the same assumption regarding the nature of the seismic performance by codes before 2003, which is considered to be inelastic. Therefore, in order to express capacity and demand in a coherent way, it is possible to employ the behavior factor for dividing the elastic current demand, as well as, multiplying the capacity.

It should be mentioned that, if the information about the fundamental period is not available (or if the structure has a particularly low period of oscillation), the $N O D E_{S_{a, d}(T)}$ and $N O D E_{S_{a, e}(T)}$ indices tend to the following expression; Eq. (13):

$$
N O D E_{P G A}=P G A_{\text {new }}-P G A_{\text {old }} .
$$

This highlights the fact that the $N O D E_{P G A}$ index differs from the one computed in Eq. (4), as no modification of capacity term for taking into account fundamental period is considered. $^{6}$

The above defined indices have formulations very similar to the one proposed by Grant et al. (2007); the main differences regard the explicit use of spectral acceleration rather than PGA, of the behavior factor and of site-specific soil category (to follow).

In addition to those discussed, it is possible to define indices expressed in terms of capacity to demand ratios, as reported in Eq. (14), similar to those computed in the NZSEE (2003) approach:

$$
\left\{\begin{array}{l}
N O D E_{P G A \text { ratio }}=\frac{P G A_{\text {old }}}{P G A_{\text {new }}} \\
\operatorname{NODE}_{S_{a}(T) \text { ratio }}=\frac{S_{d, C}\left(T_{1, \text { old }}\right)}{S_{e, D}\left(T_{1, \text { new }}\right) / q}
\end{array}\right.
$$

These indices are, in fact, those calculated in the preliminary screening phase of NZSEE guidelines, except for the coefficients cited in Sect. 4.1. The meaning of the symbols is the same already discussed for other nominal deficit indices.

In order to appreciate the advantage of considering the demand to capacity ratio, it is possible to take into consideration two different structures: a first one designed for $0.8 \mathrm{~g}$ spectral acceleration and subjected to a modern hazard estimate equal to $1.0 \mathrm{~g}$, and a second one designed for $0.1 \mathrm{~g}$, while it should be $0.3 \mathrm{~g}$ according to current standards. Taking the difference, these structures are of comparable nominal risk, but the latter is expected to undergo to more ductility demand than the former, which the ratio is able to capture. On the other hand, the use of a ratio imposes the definition of a conventional horizontal seismic capacity to those building designed in non-seismic zones, while the difference makes it possible to assume their capacity equal to zero, which, although untrue, may be rational in prioritizing conventional risk in a portfolio.

It can be noted that, in such cases as the seismic demand at the time of design was larger than the current one, the discussed risk measures can take values larger than the unity, if defined as ratio, or negative values, if defined as difference. This, in Italy, applies basically in the case of design performed after 2003, as seismic demands were, according to O.P.C.M. 3274 (2003), generally larger than current ones (see Fig. 2).

\footnotetext{
${ }^{6}$ It is to note that $P G A_{\text {old }}$ has been used for analogy with $P G A_{n e w}$, although PGA is not a concept explicit in older codes.
} 


\subsection{Fundamental period and soil conditions}

Since the spectral accelerations appearing in Eqs. (9), (10) and (14) are proxies for the base shear required by two different codes (the one enforced at the time of design and currently), it may be considered consistent to compare spectral accelerations corresponding to two different fundamental periods. Under this assumption $T_{1, \text { new }}$ and $T_{1, \text { old }}$ are, respectively, the fundamental period of the structure computed according to current code formulation and according to the code in place at time of design (e.g., for the period from 1975 to 2002, the fundamental period is computed as $T_{1, \text { old }}=0.1 \cdot H / \sqrt{B}$, where $H$ and $B$ are the height and maximum plan dimension of the building in [m]; see Petruzzelli 2013, for details). Therefore, when no response spectrum was defined (between 1909 and 1975) seismic coefficient can be treated as a constant spectral acceleration expressed in g, otherwise, code based formulations may be used according to the code that was in force in the design year.

Site classification of subsoil according to NIBC is explicitly considered in the definition of current seismic demand $S_{e, D}\left(T_{1, \text { new }}\right)$. The inclusion of site effect in the current demand, causes that, in the case of better soil conditions (e.g., type A or B with respect to type $\mathrm{C}$ soil, according to the EC8 classification, assumed by default in the case of lack of information), the nominal deficit assumes the lower possible value for that site (all other parameters being given). As it will be discussed more in detail in the following, the increasing availability in literature of nationwide soil maps and micro-zonation studies, aimed at the classification of subsoil according to current regulatory codes, makes the explicit consideration of site effect suitable.

The influence of site effect can be explicitly taken into account also in the capacity term. For example, starting from 1975 a coefficient $\varepsilon=1.3$, amplifying the seismic action, was considered in the case of deformable soils, as reported in Eq. (1). (In the context of this work, this coefficient was applied for the soil classes not referring to stiff soils according to the current classification, to follow.)

The different ways, according to which each code took site effects into consideration, may seem to produce a non-coherent computation of site effect in the capacity and demand term. It is recalled there that the aim of the approach is to compare two code requirements and assume as conventional seismic capacity the demand enforced at the time of design.

\subsection{Buildings designed in non-seismic sites}

For buildings designed for gravity loads only, that is before the inclusion of the construction site in seismic zone, design for lateral resistance was not required and the capacity $S_{d, C}\left(T_{1, \text { old }}\right)$ reduces to zero. In these cases, the NODE is equal to the current seismic demand at the site. Although it is widely known that such buildings have some seismic capacity, ${ }^{7}$ it is consistent with the approach to assign, comparatively, the largest deficit to the structures designed without any seismic provisions, as any stakeholder would seldom decide to invest less money to reduce the risk for structures seismically designed in a portfolio rather than structures designed for gravity loads only. Moreover, some may argue that within the structural class of buildings designed for gravity loads only (e.g., reinforced concrete), significant differences in terms of seismic performance exist, as the minima for

\footnotetext{
7 Some authors (e.g., Bazzurro et al. 2005) quantify the seismic coefficient for Italian RC buildings designed only for gravitational loads as $0.08-0.10 \mathrm{~g}$.
} 
elements design render very different the actual vulnerability, especially with respect to the number of story (e.g., Polese 2002). It appears possible, at least in principle, to account for this issue with a careful calibration of the behavior factors (Sect. 6). Nevertheless, the discussed strategies do not attempt to address it.

Another possible strategy for assessing the seismic capacity of structures designed in non-seismic sites concerns the possibility that the building's design against horizontal forces is not dictated by seismic considerations. This could be the case, for instance, for lightweight and large structures, such as industrial steel buildings, where design for wind actions can dominate. In order to take into account for any prescribed lateral resistance, wind design requirements and their evolution with codes, may be also accounted for in the definition of the lateral capacity, while the demand term remains the same. In fact, if the geometry of the building is known, it is possible to assess the horizontal capacity in terms of wind base shear, as provided by the code enforced at the time of design. If the mass of the building due to dead loads is given, it also possible to assess which of the two is the most demanding action and obtain an equivalent seismic capacity in terms of acceleration.

For a brief review of the evolution of wind design prescription in Italy included in the approach considered herein, the reader should refer to the Appendix-evolution of wind design in Italy, and for a more detailed one to Bartoli et al. (2011).

\subsection{Accounting for exposure}

All these nominal risk indices, as introduced in Di Pasquale et al. (2001) and applied by Grant et al. (2007), may be amplified by a measure of the exposure, or loss $(L)$, in case of failure, to get a seismic risk index (SRI) as in Eq. (15):

$$
S R I=L^{\alpha} \cdot N O D E,
$$

where $\alpha$ represents an individual versus social risk index and can assume values ranging between 0 and 1 . In fact, if $L$ is, for example, the number of average occupants of the building it is possible to maximize the social risk posing $\alpha$ equal to 1 , conversely if $\alpha$ is equal to 0 this means to have SRI in terms of individual risk. However, this means to lose the proportionality to a base-shear of the indices.

\section{Assumptions and limitations of nominal indices}

Each of the nominal deficit measures summarized in this paper implies at least some of the following assumptions, which is important to recall when evaluating their applicability:

1. compliance with regulatory codes enforced at the time of design, which implicitly means applicability to engineering structures only;

2. the methodology needs to define the capacity for those structures in sites not considered as seismically prone at the time of design (this capacity can be assessed, for example, referring to other horizontal design actions, such as wind action);

3. live loads are negligible with respect to dead loads, in order to compare seismic demand and capacity in a coherent manner and neglect changes in live loads definition over the years;

4. the demand at the time of design is considered inelastic;

5. the current demand is related to elastic spectral acceleration at the first mode period; 
6. the design demand at the time is assumed to correspond to a known return period of the seismic action. ${ }^{8}$

The definition of the behavior factor $q$, or of equivalent measures of ductility and overstrength employed in the described indices, and the way it is used in the computation of the indices, appear as one of the critical aspects, this is because the assumption that demand at the time of design can be considered inelastic is not explicit in the codes pre-2003. This implies that risk indices may not be an absolute measure of performance gap but only give priorities between different structures for which they are applied in a consistent manner (Grant et al. 2006).

The definition of behavior factors for different code requirements, for example referring to typical structural typologies, materials and construction practice and, most of all, minimum code requirements, would provide useful proxy of the actual seismic capacity of existing structures. It seems appropriate that the adopted $q$-factor should be lower for buildings designed according to older codes. For example, starting from 1996 detailed requirements for local ductility were enforced, so that, for a building designed according to this code, it seems reasonable to assume larger ductility with respect to a similar structure designed according an older code. In this way, a lower value of the nominal deficit corresponds to a more recent building. Nevertheless, the evaluation of behavior factors is a yet not completely addressed issue ${ }^{9}$ that goes beyond the purpose and scope of this work.

Given these general assumptions, it is worthwhile to highlight some pros and cons which readily emerge. Regarding the cons:

- all the discussed indices compare seismic performance reflecting different design philosophies that underlie codes at different eras (in fact, most of older Italian codes are based on admissible stress design which means linear elastic modelling at a material level, without any capacity design principle found in current codes, and current demand terms of nominal deficit indices);

- on the other hand, they assume the capacity at the time being inelastic (i.e., the code horizontal force is assumed to be comparable to linear static design of structures nowadays, which may be incorrect and requires to choose a behavior factor to apply, which is a not completely solved issue of research and practice);

- they are blind-prediction-based, while it is well known that in order to assess seismic structural performance of existing structures these have to be known in great detail (Jalayer et al. 2010; Petruzzelli et al. 2010);

- they do not allow a direct (absolute) estimate of expected loss, yet a comparison of deficit among a portfolio for which same assumptions can be made;

- any systematic deviation from code requirements is neglected, unless it is conventionally considered by means of coefficients reducing the capacity, as in the NZSEE (2003) approach (see Sect. 4.1).

\footnotetext{
${ }^{8}$ For example, 1000 years return period for structures designed within the ' 70 s and ' 80 s; G.M. Verderame, University of Naples Federico II, personal communication.

${ }^{9}$ It is to mention that NIBC and EC8 provide $q$ values ranging from 1.5 to 3 for existing buildings. Applying it to the NODE indices would mean to address the current demand term as a code-based current demand for an existing building.
} 
Regarding the pros, despite the strong limitations described above, there are quite a few as listed:

- these nominal measures of seismic risk are based on very poor information, which, in the most unfavorable case, may be only the location, year of design, and material/typology, thus applicable at regional scale; moreover, in many cases, these data are easily available from statistical analysis of the building stocks;

- they allow to explicitly to account for the evolution of seismic classification of the territory and evolution of codes, which may be reasonably believed to be the main cause of performance deficit, if any;

- being quantitative, they fit with hazard defined at a structural level, and may account explicitly for exposure;

- even if the deficit is biased due to inaccurate assumptions, they may be useful to rank priorities if they are applied consistently in a homogeneous portfolio.

\section{The NODE v.1.1 beta software}

NODE-NOminal DEficit-v.1.1 beta (see the code availability at the end of the paper) is a software tool developed as a prototype to automatically obtain the information required to compute the indices discussed for the Italian territory. NODE v.1.1 beta was developed in Mathworks MATLAB ${ }^{\circledR}$ and contains the entire evolution of seismic design codes since 1909 to today (Sect. 2), as well as the evolution of wind design in the same period (briefly summarized in the Appendix - evolution of wind design in Italy), for the whole Italian territory. ${ }^{10}$ The software allows to visualize the evolution seismic classification (Sect. 3), associating the municipality boundaries in place at the time of design, according to different census data, provided by ISTAT. Thereby the software allows to retrieve, for each Italian site, information about the year of first seismic classification, eventual de-classification, and the evolution of seismic and wind design prescriptions. Moreover, the tool includes the retrieval of hazard curves on stiff soil for the whole Italian territory, on the basis of INGV data (Stucchi et al. 2011).

The gradient of log-log approximation of hazard curve, for 11 fundamental periods ranging from 0 to $2 \mathrm{~s}$, is automatically provided for the Italian territory, which is useful for the definition of some of the risk indices described above; Eqs. (7) and (8). As an example, in Fig. 6 (left) a map of values is shown, obtained from linear regression of median PGA values from the INGV study, considering 100, 475, 1000 and 2500 year return period data. ${ }^{11}$ It can be observed that $k$ varies significantly throughout Italy with minimum and maximum values of 1.8 and 4.7 , respectively. The mean value is equal to 3.07 , which is compatible with Eurocode 8 indications.

Another information contained in the NODE v.1.1 beta software is a site effect zonation for the entire Italian territory, isles included, with a resolution of 1:100,000. (This map is a very early version of the one presented in Forte et al. 2019)

As it can be seen from Fig. 7, NODE software provides the Eurocode 8 and NIBC subsoil classification, so that the response spectrum at the site can be accordingly modified to

\footnotetext{
${ }^{10}$ NODE software does not account for local standard/specifications adopted for post-earthquake reconstruction adopted after some major events in Italy.

11 More refined maps of $k$ are given and discussed in Cito and Iervolino (2020).
} 

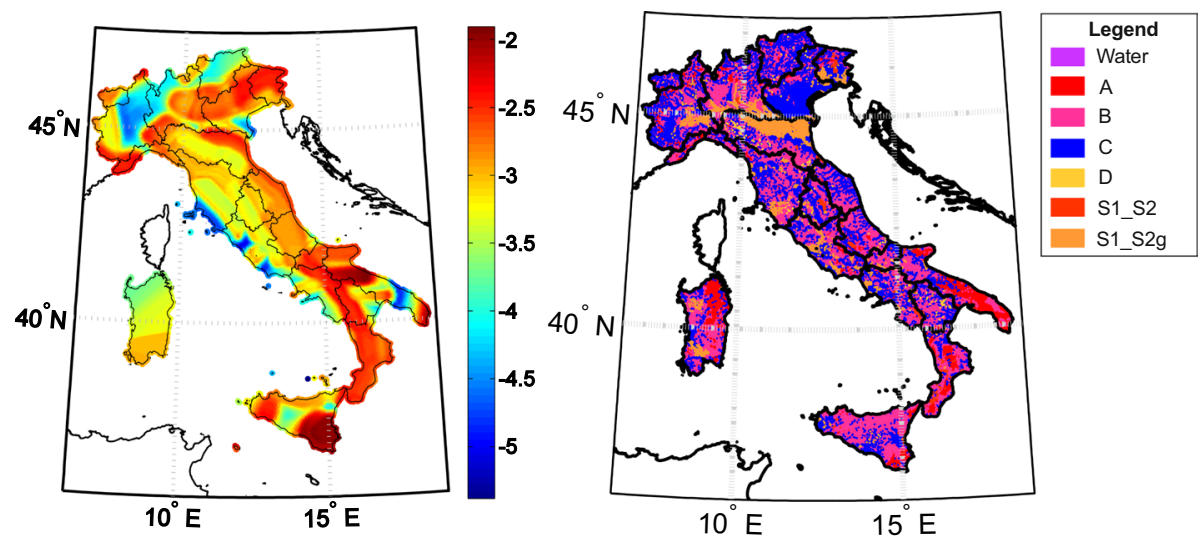

Fig. 6 Left: slope (absolute value) of PGA hazard curves for PGA, obtained from linear regression of logarithms of median INGV data, considering 100, 475, 1000 and 2500 years return periods. Right: subsoil classification according to Eurocode 8 and NIBC (Antonio Santo, written communication, 2013) (Category S1_S2 refers to subsoils potentially subjected to liquefaction (CEN 2004) on the basis of observational data from past earthquakes; category S1_S2g refers to subsoils potentially subjected to liquefaction on the basis of the prevalent geological formations)

take account for upper $30 \mathrm{~m}$ site subsoil. This information allows to compute automatically, and for large portfolios, the nominal risk indices discussed in Sect. 4 and 5: the $P G A_{\text {deficit }}$ index by Grant et al. (2007) in Eq. (4); both the indices defined by Crowley et al. (2008) in Eqs. (7) and (8); and the proposed NODE indices in Equations from (9) to (14).

The software was developed in order to reflect the quality and quantity of gathered information about the structures of the portfolio under investigation. In fact, if the information necessary to the definition of fundamental period of the structure is not available, the nominal indices are automatically computed in terms of PGA, that is to say according to Eqs. (4), (7), (13), and the first in (14). On the contrary, if the available information allows the code-based definition of fundamental period, the computed risk indices are those reported in Eqs. (8), (11), (12), and the second in (14). It is worthwhile to specify that, according to seismic codes that have been in effect in Italy since 1975 to date (that is to say since the first introduction of the response spectrum), the formulations for the definition of fundamental period only required to know the building dimensions and construction material.

The program is operated via the following steps: (1) definition of nominal seismic requirements; (2) definition of parameters for seismic assessment; (3) definition of wind design parameter, if any; (4) assessment of nominal indices. These steps, described in the following, may be deployed by data entry for each specific structure through the graphic user interface depicted in Fig. 7.

Since the described procedures are aimed at the large-scale seismic risk prioritization analysis, the NODE v.1.1 beta software is also able to load a spreadsheet file with required basic information, for the analysis of large structural portfolios. 


\subsection{Step-1: definition of nominal seismic requirements}

In order to perform the assessment, it is necessary to enter the geographical coordinates of the site or location name. In both cases the software automatically defines the municipality name, used in Italian seismic classification from 1909 to 2008 (Fig. 7, box 1a). Once the design year is entered by the user, the seismic maps for design year code and reference year (2009) code are returned (if the coordinates are entered the software returns the exact acceleration for the site according to NIBC, otherwise the value representative for the municipality is returned as that corresponding to the centroid of the polygon defining municipality boundaries). From this step it is possible to immediately check the seismic category for seismic design, the design acceleration, if any, and whether the building was designed for vertical loads only (Fig. 7, box 1b-1c).

\subsection{Step-2: definition of parameters for seismic assessment}

After step one is completed, three boxes become editable: the first is relative to the fundamental period; the second to the foundation soil and the last one to the behavior factor (Fig. 7, box 2).

The first box contains those parameters necessary for the automatic computation of fundamental period depending on code enforced in the design year. As previously stated, if this information is not available, that is, it is impossible to retrieve building height and/or maximum plan dimension and construction typology, nominal deficit indices can be computed in terms of PGA. This makes year of construction and site location the only strictly necessary for the assessment.

The second box is relative to the definition of subsoil classification and a topographic seismic action amplification coefficient, according to NIBC (which is not changed in the upgrade from 2008 to 2018). The NODE software automatically assigns site classification according to NIBC and a notification message notifies the user about the automatic attribution of subsoil

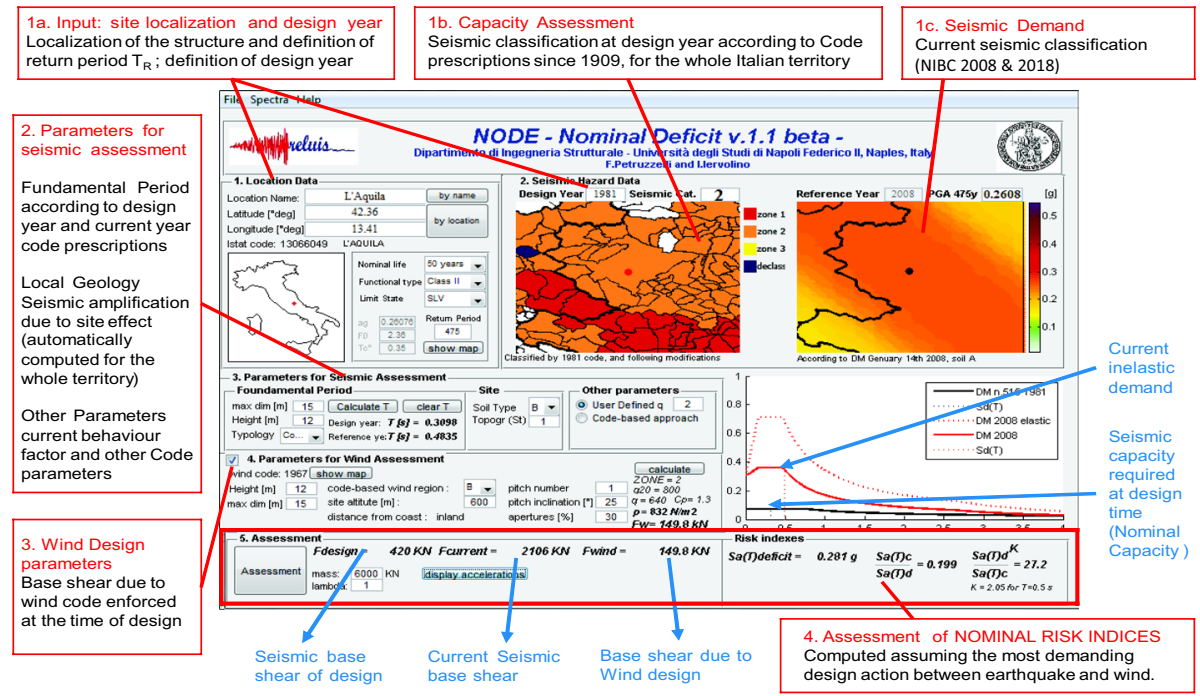

Fig. 7 NODE v.1.1 beta graphic user interface 
category, otherwise subsoil category C according to CEN (2004) is considered by default. In case the soil classification study within the software provides an S1 or S2 soil category, that is a soil potentially subjected to liquefaction, the tool prompts a warning message to the user. In any case, the site classification can be modified by the user, if more detailed information is available. The same applies to the topographic amplification coefficient, considered equal to one by default and modifiable by user entry.

The last box allows the definition of a user-defined behavior factor or the use a code-based one, for the current seismic demand. Selecting this latter option, a new window appears containing the NIBC08 approach for the definition of the behavior factor for a new building and other parameters that can be changed in the capacity term, according to design year code. The behavior factor is, by default, equal to 1 , but similarly to the other parameters, it can be modified by the user, and the seismic risk indices are accordingly computed.

\subsection{Step-3: definition of wind design parameter}

In order to provide with the possibility of including the horizontal capacity due to wind design in the assessment, the box Parameters for wind assessment must be checked (Fig. 7, box 3), otherwise it is possible to go to the next step. In the former case, several parameters appear, according to the wind code enforced at the time of design. These parameters regard essentially geometry of the building, pitch number and inclination, aperture percentage and site altitude (see the Appendix - evolution of wind design in Italy). Other parameters, necessary for the evaluation of wind base shear, are automatically calculated by the software according to the code retrieved by design age information. If the mass of the building is entered, the seismic base shear is also calculated and compared to the wind base shear, in order to assess the most demanding design action among wind and earthquake at the time of construction and quantify the capacity term accordingly.

\subsection{Step-4: assessment of nominal indices}

Once the previous steps are performed, by pressing the Assessment button (Fig. 7, box 4), the software automatically computes the base shears at the time of design and according to NIBC. Switching to the corresponding spectral accelerations the mentioned nominal deficit indices are computed; i.e., Eqs. (4), (7), (8), (11), (12), (13), (14). In Fig. 8, these indices are reported in the bottom right corner. The elastic and inelastic demand spectra and the capacity spectrum (where defined, otherwise the seismic coefficient) are always plotted for a visual evaluation of nominal gap. Finally, it is possible to export files with summary of input data and results including response spectra and, eventually, seismic coefficient according to the current design code and the one enforced at the design time.

\section{Illustrative application}

As an illustrative application of the large-scale prioritization software, NODE v.1.1 beta, the described indices have are applied to a real case study, consisting in a portfolio composed of 19 plants, each of which is made of several structures, for the production of parts for the automotive industry, spread throughout the Italian territory (Fig. 8). 
Table 2 Soil category and structural composition of the case-study portfolio

\begin{tabular}{|c|c|c|c|c|c|c|c|}
\hline Plant ID & $\begin{array}{l}\text { First cos- } \\
\text { truct. year }\end{array}$ & PGA [g] & Soil cat. & \# Struct. units & \# Prod. struct. & OLR & ELR \\
\hline PLANT-01 & 1971 & 0.256 & B & 8 & 4 & 0.50 & 0.48 \\
\hline PLANT-02 & 1988 & 0.242 & $\mathrm{C}$ & 3 & 2 & 0.22 & 0.43 \\
\hline PLANT-03 & 1988 & 0.240 & $\mathrm{C}$ & 2 & 1 & 0.06 & 0.43 \\
\hline PLANT-04 & 1977 & 0.240 & $\mathrm{C}$ & 14 & 10 & 0.67 & 0.14 \\
\hline PLANT-05 & 1993 & 0.198 & $\mathrm{C}$ & 14 & 8 & 0.27 & 0.43 \\
\hline PLANT-06 & 1993 & 0.198 & $\mathrm{C}$ & 2 & 1 & 0.11 & 0.43 \\
\hline PLANT-07 & 1987 & 0.191 & B & 5 & 5 & 0.11 & 0.14 \\
\hline PLANT-08 & 1934 & 0.165 & $\mathrm{C}$ & 15 & 6 & 0.58 & 1.00 \\
\hline PLANT-09 & 1973 & 0.157 & $\mathrm{D}$ & 8 & 4 & 0.58 & 0.43 \\
\hline PLANT-10 & 1974 & 0.147 & B & 6 & 4 & 0.44 & 0.43 \\
\hline PLANT-11 & 1988 & 0.143 & B & 4 & 3 & 0.21 & 0.43 \\
\hline PLANT-12 & 2001 & 0.108 & $\mathrm{C}$ & 2 & 1 & 0.18 & 0.43 \\
\hline PLANT-13 & 1963 & 0.082 & $\mathrm{C}$ & 7 & 2 & 0.18 & 0.26 \\
\hline PLANT-14 & 1968 & 0.081 & B & 5 & 2 & 0.26 & 0.43 \\
\hline PLANT-15 & 1969 & 0.076 & A & 14 & 6 & 0.89 & 0.35 \\
\hline PLANT-16 & 1962 & 0.058 & B & 14 & 12 & 0.78 & 0.23 \\
\hline PLANT-17 & 1919 & 0.056 & B & 4 & 4 & 0.78 & 0.42 \\
\hline PLANT-18 & 1976 & 0.046 & B & 7 & 4 & 0.28 & 0.43 \\
\hline PLANT-19 & 1968 & 0.040 & B & 6 & 4 & 1.00 & 0.58 \\
\hline
\end{tabular}

In Table 2, the PGA with 475 years return period on rock at the site according to the official Italian hazard map (Stucchi et al. 2011) is given along with the number of individual structural units for each plant, with specification of their use. In fact, it was possible to classify the structures in the plants according to their occupancy; i.e., distinguishing:

Fig. 8 Case-study plants on the Italian map of PGA with 475 years return period on rock (Stucchi et al. 2011)

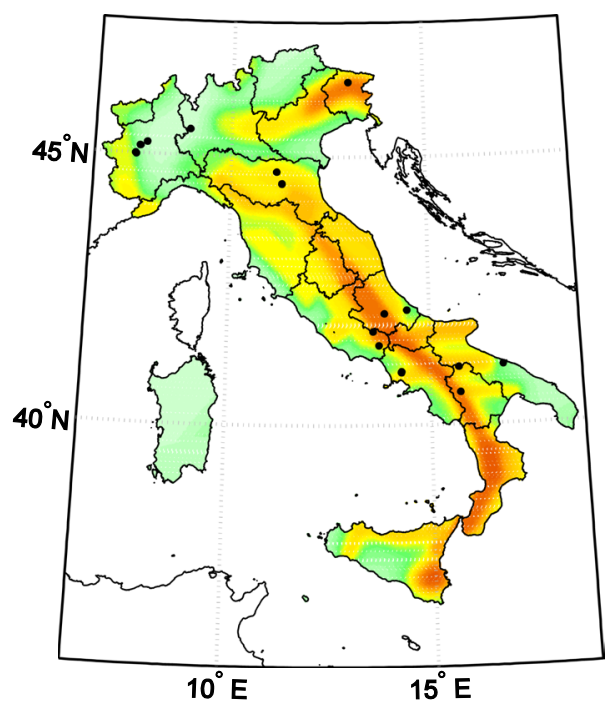


production structures, utilities, storage structures, offices. The portfolio is made of 140 individual structural units, of which 83 are workshops for production, 29 are offices, 17 are utilities and 11 are storage buildings. Referring to the structural typology, the most part is of production structures contributed by precast reinforced concrete (PRC) structures $(60 \%$ of the total) and the remaining part is composed of steel structures (40\%). However, steel structures present, in general, bigger plan dimensions than PRC structures; in fact, the 58\% of the whole covered area used for production is relative to steel structures, while the $42 \%$ is relative to PRC structures. Regarding the year of construction, more than one third of the portfolio's structures were built in the ' $60 \mathrm{~s}$ and more than the $50 \%$ of the structures were built before 1980 .

In 15 of the 19 plants it was possible to gather information about shear wave velocity in the top $30 \mathrm{~m}$ of subsoil under the foundation layer, and associate to each plant the subsoil class according to EC8. In the other cases, were made based on geological information from the map of Fig. 6 (right). Such soil site classes are also given in Table 2.

For confidentiality issues, the exposure of each plant is given in terms of occupancy loss ratio (OLR) and exposure loss ratio (ELR) in Table 2. The former is the ratio of the employees in the plant divided by the largest number of employees among the portfolio, while the ELR, is the ratio of the insured value of the plant divided by the maximum insured value across the portfolio. These ratios provide the relative importance, in terms of exposure, of each plant. Comparing with the PGA from the map of Fig. 8, it can be observed that the most exposed plants in terms of number of occupants are characterized by an average economic loss and are located in the less hazardous sites.

The application given in the following is only for illustrative purposes, while for more details about the risk analysis of the portfolio the interested reader should see Petruzzelli (2013) for details. In particular, the prioritization indices are computed referring to production structures, since the functionality of the whole plant depends on them and most of the exposed values (workers, contents, activities) are typically located in, or related to, them.

The production structures are identified with a code of the type STRUCTURE_ID $=P L \_W S \# \_S U \# \_M A T \_Y E A R$, where $P L$ indicates the plant name; WS\# the workshop or production building or aggregate; $S U \#$ the structural unit composing the aggregate (\# is a progressive number); MAT represents the structural material (ST stands for steel and PRC for precast reinforced concrete) and YEAR is the year of design.

A first ranking was performed computing NODE in terms of PGA; in particular, the $N O D E_{P G A, s o i l}$ index can be computed according to Eq. (13), considering the PGA as the spectral ordinate and accounting for soil conditions. Results are shown in Fig. 9 (top), where the PGA on rock with 475 years return period is also provided. The figure also provides the $S R I_{P G A \text {,soil }}$ index, computed according to Eq. (15), which reflects the influence of the exposure on the nominal deficit index-based ranking.

The indices just described did not require on-site inspection for their computation. Conversely, the computation of spectral-acceleration-based indices that account for basic dynamics characteristics of the structure, that is the fundamental period, requires more information. Therefore, the plants composing the portfolio were inspected. Moreover, in order to take into account the ductility and overstrength of existing buildings designed in different years, according to different structural codes, simplified assumptions were made about the behavior factor $q$ in Eq. (13). Regarding steel structures, if designed before the 1975 a $q$ value of 1.5 was assumed; if designed between 1975 and 1996, $q$ was taken equal 

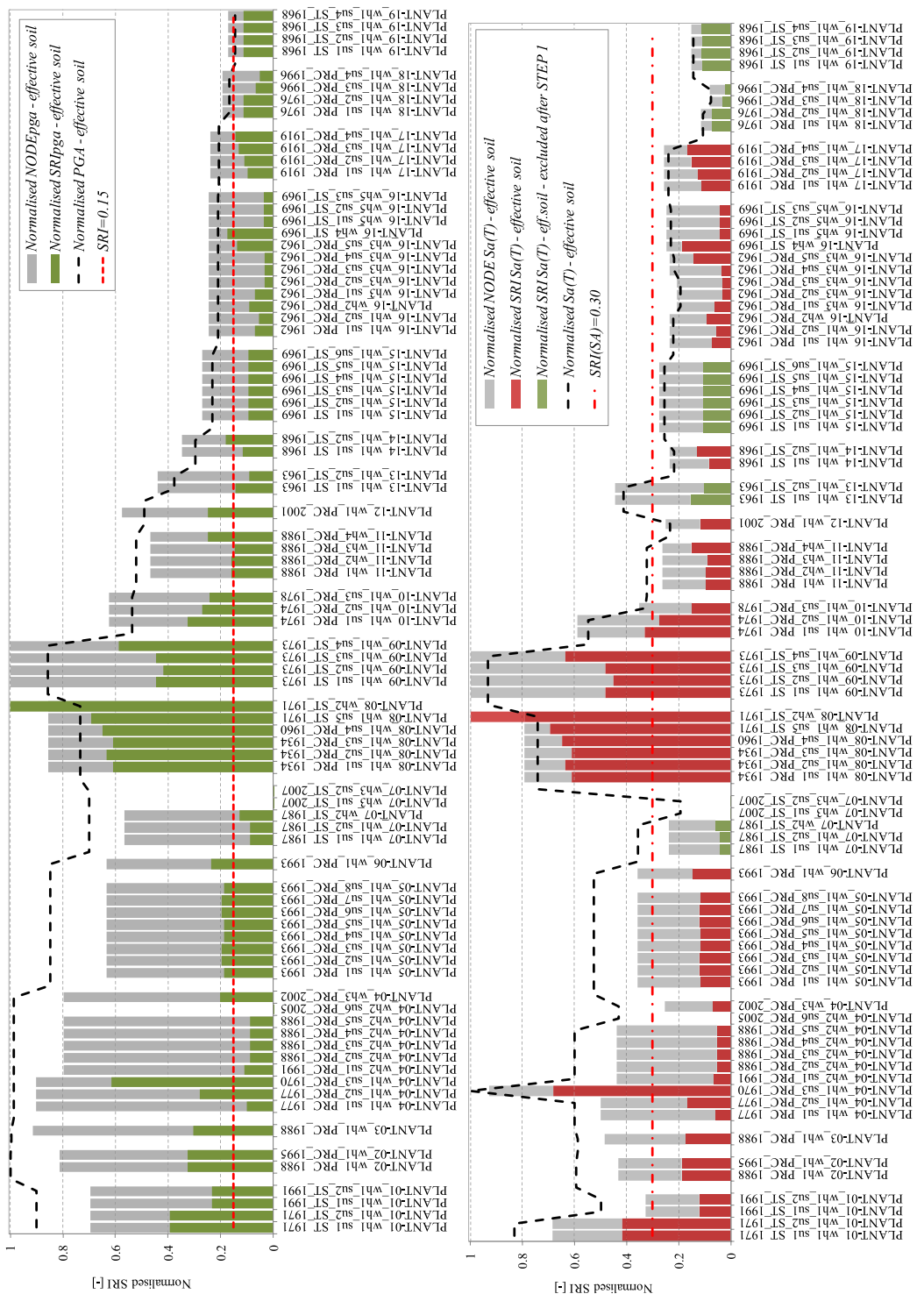

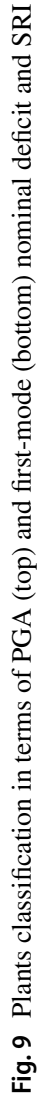


to 2.5 and, finally, if designed after 1996, a $q$ factor equal to 3.5 was assumed. Concerning precast structures, a behavior factor equal to 1.5 was assumed for structures designed before 1987; $q$ equal to 2.5 is assumed between 1987 and 1996 and 3.5 after 1996 . $^{12}$ The results of this more detailed analysis are shown in Fig. 9 (bottom), in which the $N O D E_{S a(T) \text { soil }}$ index is represented in grey and the $S R I_{S a(T), \text { soil }}$ in red, except for plants characterized by an level of risk (arbitrarily considered low) as resulting from the classification in terms of PGA (represented in green).

In the $N O D E_{S a(T), \text { soil }}$ ranking, the influence of structural dimensions clearly emerges, causing the structures characterized by lower fundamental periods to take place in the most risk-prone portion of the ranking. As an example, the structure PLANT-04_whl_ su3_PRC_1970, that is a large PRC structure designed in 1970, places on the top of the $N O D E_{S a(T), \text { soil }}$ ranking, while in the $N O D E_{P G A \text {,soil }}$ ranks in the middle. The influence of the construction material on the $N O D E_{S a(T), \text { soil }}$ tends to reduce the differences in the nominal deficit of steel and PRC structures. An example of larger fundamental periods due to construction material (steel) and geometric dimensions is the PLANT-01_wh1_su1_ST_1991, that is an average size steel building for which the $N O D E_{S a(T), \text { soil }}$ is significantly lower than $N O D E_{P G A, s o i l}$. For PLANT-07, characterized by recent steel structures, the shifting to the bottom of the ranking is a consequence of larger fundamental periods of its structures and of higher behavior factors too. Regarding the ranking in terms of $S R I_{S a(T), \text { soil }}$, it is worth noting that, even if the trend looks similar to the one observed for $S R I_{P G A \text {,soil }}$, there are cases in which the differences are significant.

More than the $50 \%$ of the structures were not designed for seismic action because at the time of design the site of construction was not included in national seismic classification. The achieved level of knowledge is enough to compute, by means of the NODE v. 1.1 beta, the horizontal wind action according to the code enforced at the time of design (again, see Petruzzelli 2013, for details). In Fig. 10 a comparison between the $N O D E_{S a(T), \text { soil }}$ and $S R I_{S a(T), s o i l}$ indices obtained both considering and neglecting the wind design for the definition of the horizontal capacity is shown. In about $70 \%$ of the cases $(58 / 83)$ the most demanding action at the time of design was the one due to the wind action.

Of these cases, 10 are relative to structures located in sites where a seismic code was enforced at the time of design, in the remaining 48 cases the site was not classified. It can be noted that in some cases, mainly steel structures and structures with large plan developments, a significant reduction of the deficit index is achieved considering wind design. This is the case of PLANT-09 that reduces the nominal deficit of its structures so that it is no more the most risk-prone plant. Similar considerations can be applied to PLAN-16 and PLANT-18, some structures of which reduces their nominal deficit to zero. Conversely, in the case PRC structures designed in classified sites, the weight of such structures makes the earthquake design, in general, more demanding than wind one (e.g. plants from PLANT-02 to PLANT-06).

\subsection{Comparison of NODE with other indices}

A comparison of the $N O D E_{P G A, \text { soil }}$ index with other indices discussed is undertaken; again, by means of the software NODE v.1.1 beta. In particular, the $P G A_{\text {deficit }}$ by Grant et al.

\footnotetext{
12 It is worth to underline that the values given above represent just an example of reasonable $q$ factors to be applied in prioritization analyses (i.e. for a relative measure of seismic risk).
} 


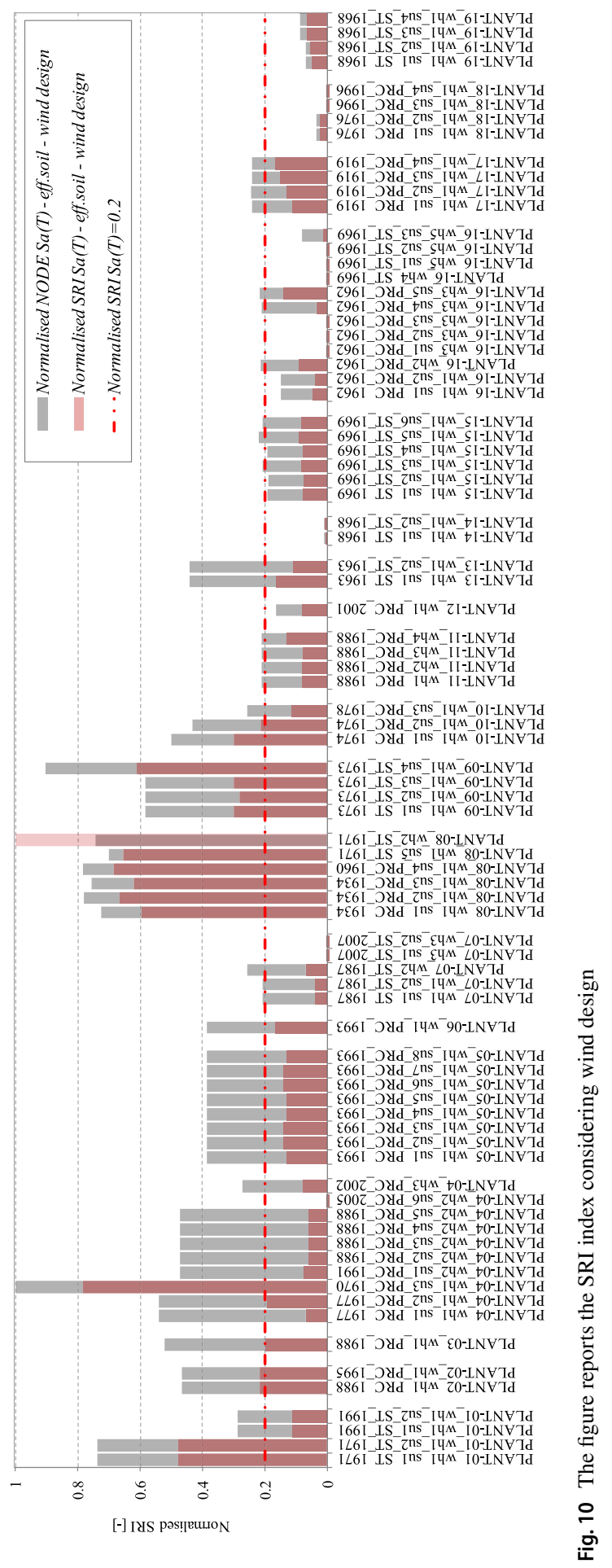




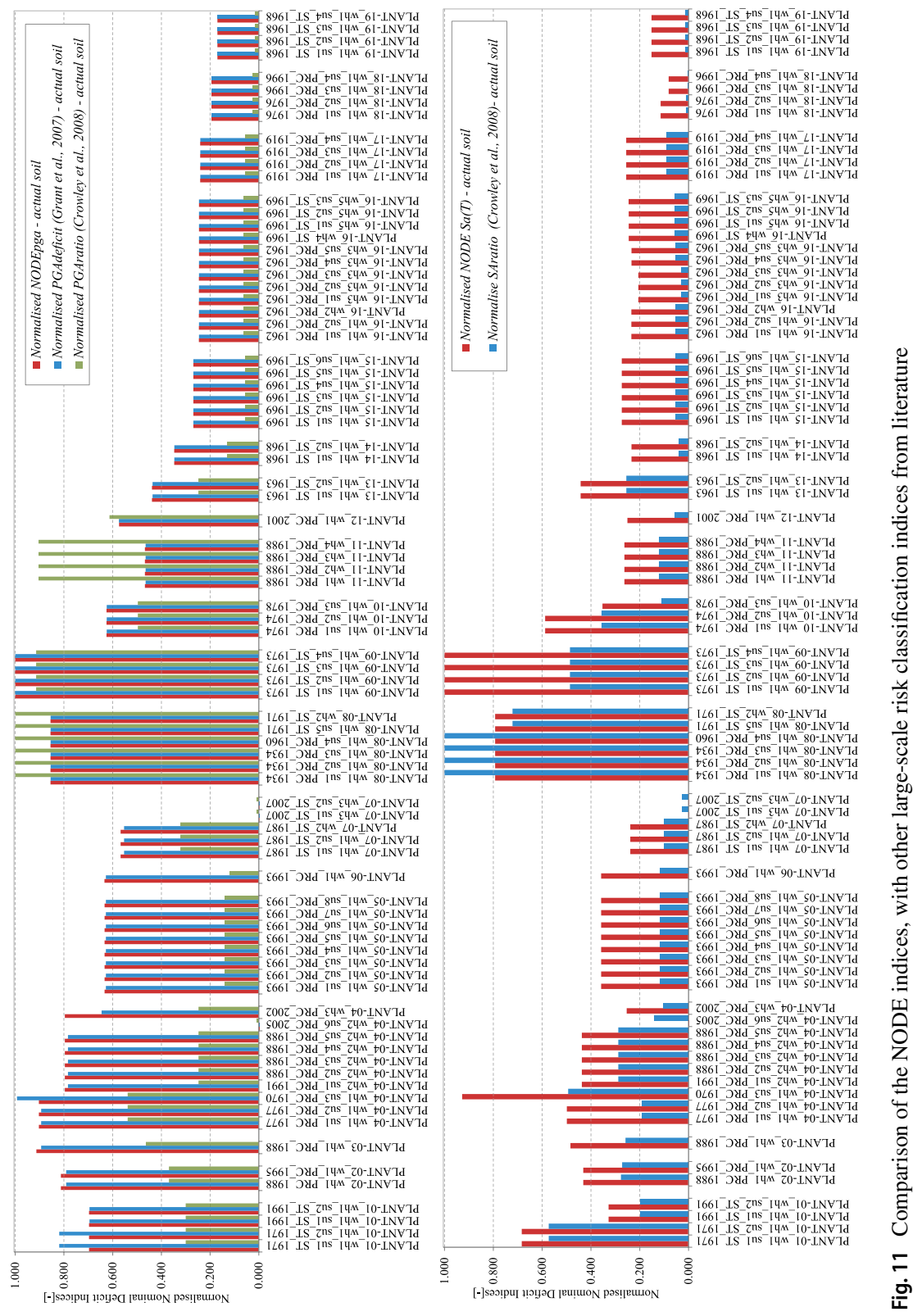


(2007), and those presented in Crowley et al. (2008), referred to as $P G A_{\text {ratio }}$ and $S A_{\text {ratio }}$. In Fig. 11 ( top) such a comparison is shown. It can be noted that no substantial differences can be observed in the ranking obtained by means of the first two indices. The $P G A_{\text {deficit }}$ takes into account the fundamental period of the structure in the definition of the effective PGA, for this reason some slight differences in the two rankings can be observed for plant from PLANT-01 to PLANT-07. The small difference can be also explained with the formulations adopted for the computation of the fundamental period. This leads to the conceptual difference between the two indices: while the $P G A_{\text {deficit }}$ index represents a comparison of the actual seismic demand with a manipulation of the one enforced at the time of design, the NODE is simply the comparison of the current seismic demand with the one actually employed by the professional in the original design. The latter is the reason for the adoption of code-based formulation for the computation of the fundamental period.

The ranking obtained by the computation of the $P G A_{\text {ratio }}$ index is substantially different from those described above. This is related to the assumption of a seismic capacity for the structures located in non-classified sites equal to $0.05 \mathrm{~g}$, as needed for indices based on a ratio. This value is relatively high with respect to the average seismic capacity observed in the portfolio. This explains the apparent (due to the normalized plot) shifting to the bottom of the ranking of all the plants except for PLANT-08, PLANT-09 and PLANT-11. Considering the absolute values of the $P G A_{\text {ratio }}$, rather than the normalized ones, the increasing of the deficit ratio for all the plants designed in non-seismic zone is observed, so that they approach the average $P G A_{\text {ratio }}$ over the portfolio. For these reasons, it can be argued that the adoption of indices based on a ratio, implying to choose a value of seismic capacity for structures not designed for horizontal forces, substantially affects the ranking, and should be carefully evaluated.

In Fig. 11 (bottom) the comparison of the rankings based on $N O D E_{S a(T), s o i l}$ and $S A_{\text {ratio }}$ is shown. The index proposed by Crowley et al. (2008) contains more information regarding the hazard at the site than the corresponding NODE index. In fact, it employs the gradient of the logarithmic hazard curve as a measure of the hazard at the site. Looking at Fig. 11, it can be observed that, besides some differences due to the specific $k$ values at the specific site (e.g. PLANT-09) the trends of the two rankings are almost the same, therefore the two indices produce similar scales of priority.

\section{Conclusions}

In the paper, some nominal indices for the assessment of conventional seismic risk of a large building stock have been addressed, along with some possible evolutions as well as a discussion of pros, cons, and limitations.

Nominal risk indices were developed in the literature because, at large scales, the limited amount of time and resources make a refined assessment of seismic risk, or even an inspection of each structure of the portfolio under investigation, unsuitable and the necessity for multi-level approaches arises. These approaches are usually based on a first screening phase, aimed at the selection of the portion of buildings at highest risk, deserving further investigation. This prioritization phase generally requires the knowledge of data such as site location, year of design and main geometry. This information is usually only enough to assess the seismic risk of a structure in a conventional way, employing nominal indices comparing the current seismic demand to a conventional seismic capacity related to code requirements at the epoch of design. Because this choice is strictly connected to the 
Table 3 Summary of the codes for wind design in Italy considered in the proposed approach

\begin{tabular}{ll}
\hline Year & Code \\
\hline 1964 & CNR-UNI 10,012/64 \\
1967 & CNR-UNI 10,012/67 \\
1978 & DM LL PP 03/10/1978 n.18,407 \\
1982 & DM LL PP 12/02/1982 and Circ. M LL PP n.22,631 \\
1985 & CNR 10,012/85 \\
1996 & DM LLPP 16/01/1996 and Circ. M LL PP n.156 \\
2006 & CNR/DT206/06 \\
2008 & DM LL PP 14/01/2008 \\
2008 & CNR/DT 207/08 \\
\hline
\end{tabular}

evolution seismic codes requirements and classification of the territory, the study referred to Italy. In fact, a review of Italian seismic code requirements was provided and the evolution of seismic provisions over years was first discussed in the study.

The final aim was to introduce the NODE software. This software allows the automatic computation of all the indices discussed, even for large portfolios of engineered structures, considering for the different level of information available. In fact, the software contains the site-by-site evolution of seismic hazard since 1909, the corresponding structural code requirements and wind design requirements since the same year. If the information necessary to the definition of fundamental period of the structure is not available, the nominal indices are automatically computed in terms of PGA; otherwise, they are computed in terms of spectral acceleration.

As shown by means of the illustrative application, which refers to a large portfolio of structures belonging to the plants of an automotive parts manufacturer in Italy, NODE is believed to be a potential support for the large-scale prioritization for seismic risk assessment. Finally, in those cases for which the nominal indices discussed in the paper apply, the approach described could be exported in other countries where similar information about the evolution of building codes can be gathered.

\section{Appendix: Evolution of wind design in Italy}

The first Italian guidelines for the definition of wind loads were contained in the National Research Council (CNR in the following) document no.10,012 of 1964. The document also provided the first Italian map of reference kinetic pressures, unchanged in CNR guidelines of 1967. Italian territory was divided into four zones, with a reference kinetic pressure ranging between 0.6 and $1.2 \mathrm{kN} / \mathrm{m}^{2}$. The design wind pressure was defined as the product of a shape and exposure coefficient, a slenderness coefficient, and the kinetic pressure. The first compulsory document for the quantification of wind loads was the D.M. no. 18,407 of 10/03/1978, which implemented the CNR guidelines approach. The CNR instructions of 1981, introduced the concept of reference wind speed, defined as the wind speed measured at $10 \mathrm{~m}$ of height, on open field, averaged on $10 \mathrm{~min}$ and associated to a return period of 50 years. In 1982, a ministry decree (D.M. of 2/12/1982) and its explanatory document (Circolare M.LL.PP. no.22,631 of 05/24/1982) cancelled these guidelines introducing again the approach of the previous code. A significant change in wind design was issued with CNR guidelines of 1985 . 
This guideline remained the reference for wind design till 1996, when the D.M. of 01/16/1996 and its explanatory document (Circolare M.LL.PP. no.156 of 07/04/1996) were issued. By means of these codes the wind design was radically renewed and the wind pressure was defined as the product of the reference kinetic pressure, the exposure, shape, and dynamic coefficients. Moreover, a new map of wind speeds, implementing the recent improvements in wind engineering, replaced the 1967 map of reference pressures (Ballio et al. 1999). Finally, the more recent CNR-DT guidelines of 2008 implemented several relevant theoretical and design aspects. In Table 3 a summary of Italian wind design codes and guidelines, implemented in the NODE v.1.1 beta software, is given.

Acknowledgements Authors wish to thank Helen Crowley (EUCENTRE) and an anonymous reviewer for the helpful comments on the manuscript of this paper.

Funding Open access funding provided by Università degli Studi di Napoli Federico II within the CRUICARE Agreement. The present work was supported in part by the project ReLUIS-DPC 2010-2013, funded by Presidenza del Consiglio dei Ministri, Dipartimento della Protezione Civile (DPC).

Availability of data and material All discussed data relevant for this study are embedded in the NODE software.

Code availability The NODE software is available at: http://wpage.unina.it/iuniervo/NODE.exe. It requires the MATLAB Compiler Runtime 7.11, which is available at http://wpage.unina.it/iuniervo/MCRInstaller. exe. Also note that in some cases it requires the Microsoft Visual C++ (2005) available at http://wpage. unina.it/iuniervo/vcredist_x86.EXE.

\section{Declarations}

\section{Conflict of interest None.}

Open Access This article is licensed under a Creative Commons Attribution 4.0 International License, which permits use, sharing, adaptation, distribution and reproduction in any medium or format, as long as you give appropriate credit to the original author(s) and the source, provide a link to the Creative Commons licence, and indicate if changes were made. The images or other third party material in this article are included in the article's Creative Commons licence, unless indicated otherwise in a credit line to the material. If material is not included in the article's Creative Commons licence and your intended use is not permitted by statutory regulation or exceeds the permitted use, you will need to obtain permission directly from the copyright holder. To view a copy of this licence, visit http://creativecommons.org/licenses/by/4.0/.

\section{References}

Angeletti P, Bellina A, Guagenti E, Moretti A, Petrini V (1988) Comparison between vulnerability assessment and damage index. In:Proceedings of 9th world conference on earthquake engineering, TokyoKyoto, Japan, pp 181-186

ATC (1978) Tentative provisions for the Development of Seismic Regulations for Buildings, report No. ATC 3-06, Applied Technology Council, Redwood City, CA

ATC (1985) Earthquake Damage Evaluation Data for California, report No. ATC 13, Applied Technology Council, Redwood City, CA

ATC (2004) Rapid Visual Screening of Buildings for Potential Seismic Hazards Training Manual, report No. ATC 21-T, Applied Technology Council, Redwood City, CA

Ballio G, Lagomarsino S, Picardo G, Solari G (1999) probabilistic analysis of Italian extreme winds: reference velocity and return criterion. Wind Struct 2(1):51-68 
Bartoli G, Ricciardelli F, Solari G (2011) Historical evolution of Italian regulations on wind actions on structures and its implications on the design of steel structures. In: Proceedings of XXIII Congresso CTA: Le Giornate Italiane dell'Acciaio, Ischia 9-12/10/2011, Italy (in Italian)

Bazzurro P, De Sortis A, Mollaioli F (2005) Seismic risk of Italian reinforced concrete frame buildings. In: Proceedings of international conference on structural safety and reliability, ICOSSAR 2005, Rome, pp 2765-2772

Benedetti D, Petrini V (1984) On seismic vulnerability of masonry buildings: proposal of an evaluation procedure. L'industria delle Costruzioni 18:67-68 (in Italian)

Bommer JJ, Abrahamson NA (2006) Why do modem probabilistic seismic-hazard analyses often lead to increased hazard estimates? Bull Seismol Soc Am 96:1967-1977

Borzi B, Crowley H, Pinho R (2008) Simplified pushover-based earthquake loss assessment (SP-BELA) method for masonry buildings. Intl J Arch Herit 2(4):353-376

Braga F, Dolce M, Liberatore D (1982) A statistical study on damaged buildings and an ensuing review of the M.S.K-76 scale. In: Proceedings of 7 th European conference on earthquake engineering, Athens, Greece

Braga F, Dolce M, Liberatore D (1985) Statistical analyses of damage data from 23.11.80 Italy earthquake. In: Proceedings ofItaly workshop on seismic hazard and risk analysis, Varenna, Italy

Calvi GM (1999) A displacement-based approach for vulnerability evaluation of classes of buildings. J Earthq Eng 3(3):411-438

Calvi GM, Pinho R, Magenes G, Bommer JJ, Restrepo-Velez LF, Crowley H (2006) Development of seismic vulnerability assessment methodologies over the past 30 years. ISET J Earthq Technol 43(3):75-104

CEN (2004) European Standard EN 1998-3: Eurocode 8: design of structures for earthquake resistance. Part 3. Assessment and retrofitting of buildings. Comité Européen de Normalisation, Brussels

Cito P, Iervolino I (2020) Peak-over-threshold: quantifying ground motion beyond design. Earthq Engn Struct Dyn 49(5):458-478

Crowley H, Colombi M, Calvi GM, Pinho R, Meroni F, Cassera A (2008) Application of a prioritisation scheme for seismic intervention in school buildings in Italy. In: Proceedings of 14th world conference on earthquake engineering, October 12-17,2008, Beijing, China

Crowley H, Colombi M, Borzi B, Favarelli M, Onida M, Lopez M, Polli D, Meroni F, Pinho R (2009) A comparison of seismic risk maps for Italy. Bull Earthq Eng 7:149-180

Di Pasquale G, Fralleone A, Pizza AG, Serra C (1999a) Synthesis of the code evolution from the Royal decree issued after the Messina and Reggio earthquake up to the first Ministry decree issued after the law n.64/74. In: De Marco, Martini (eds) La classificazione e la normative sismica italiana dal 1909 al 1984, Istituto Poligrafico e Zecca dello Stato, Roma

Di Pasquale G, Fralleone A, Pizza AG, Serra C (1999b) Relevant changes to the Italian seismic Code from 1909 to 1975 - a synoptic table In: De Marco, Martini (eds) La classificazione e la normative sismica italiana dal 1909 al 1984, Istituto Poligrafico e Zecca dello Stato, Roma

Di Pasquale G, Orsini G, Severino M (2001) Modello di valutazione di un indice di rischio sismico per edifici, Proc. X Congresso Nazionale ANIDIS L'ingegneria sismica in Italia, Potenza-Matera (in Italian)

Di Pasquale G, Orsini G, Romeo RW (2005) New developments in seismic risk assessment in Italy. Bull Earthq Eng 3:101-128

D.M. (2008) Decreto Ministeriale del 14/1/2008, Norme Tecniche per le Costruzioni. G.U. della Repubblica Italiana n.29 (in Italian)

D.M. (2018) Decreto Ministeriale del 17/1/2018, Norme Tecniche per le Costruzioni. G.U. della Repubblica Italiana $\mathrm{n} .42$ (in Italian)

Forte G, Chioccarelli E, Cito P, De Falco M, Santo A, Iervolino I (2019) Seismic soil classification of Italy based on surface geology and shear-wave velocity measurements. Soil Dyn Earthq Eng 122:79-93

Gattesco N, Franceschinis R, Zorzini F, Grimaz S, Barazza F, Leita P, Malisan P (2011) Soglie di priorità per l'adeguamento sismico di edifici scolastici costruiti o ristrutturati prima dell'entrata in vigore delle NTC2008. In: Proceedings of XIV Convegno nazionale Ingegneria Sismica in Italia, ANIDIS, Bari. Italy. (In Italian)

Goretti A, Di Pasquale G (2004) Building inspection and damage data for the 2002 Molise, Italy, earthquake. Earthq Spectra 20(S1):S167-S190

Grant DN, Bommer JJ, Pinho R, Calvi GM (2006) Defining priorities and timescales for seismic intervention in school buildings in Italy, research report ROSE 2006/03. IUSS Press, Pavia

Grant DN, Bommer JJ, Pinho R, Calvi GM, Goretti A, Meroni F (2007) A prioritization scheme for seismic intervention in school buildings in Italy. Earthquake Spectra 23(2):291-314

Grases J, Cascante G, Gajardo E (1992) Earthquake hazard mapping for seismic design: a new approach. Proceeding of the Tenth Word Conference on Earthquake Engineering, Madrid, Vol.1, pp. 5777-5782 
Grimaz S, Slejko D, Cucchi F, Barazza F, Biolchi S, Del Pin E, Franceschinis R, Garcia J, Gattesco N, Malisan P, Moretti A, Pipan M, Prizzon S, Rebez A, Santulin M, Zini L, Zorzini F (2016) The ASSESS project: assessment for seismic risk reduction of school buildings in the Friuli Venezia Giulia region (NE Italy). Boll Geofis Teorica Appl 57(2):111-128

Iervolino I, Petruzzelli F (2011) NODE v.1.0 beta: attempting to prioritize large-scale seismic risk of engineering structures on the basis of nominal deficit. In: Proceedings of XIV Convegno Nazionale "L'Ingegneria Sismica in Italia", Bari, Italy, paper no 975

Iervolino I, Fabbrocino G, Manfredi G (2004) Fragility of standard industrial structures by a response surface-based method. J Earthq Eng 8(6):927-946

Iervolino I, Manfredi G, Polese M, Verderame GM, Fabbrocino G (2007) Seismic risk of R.C. building classes. Eng Struct 29:813-820

ISTAT (2001) $14^{\circ}$ Censimento Generale della Popolazione e delle Abitazioni. Istituto Nazionale di Statistica. https://www.istat.it/it/censimenti-permanenti/censimenti-precedenti/popolazione-e-abitazioni/ popolazione-2001 (In Italian)

Jalayer F, Iervolino I, Manfredi G (2010) Structural modeling uncertainties and their influence on seismic assessment of existing R.C. structures. Struct Saf 32(3):220-228

JRC (2013) Guidelines for deriving seismic fragility functions of elements at risk: Buildings, lifelines, transportation networks and critical facilities, Syner-G Reference Report-4, European Commission Joint Research Centre-Institute for the Protection and Security of the Citizen, Luxembourg Publications Office of the European Union

Kappos AJ, Panagopoulos G, Panagopoulos C, Penelis G (2006) A hybrid method for the vulnerability assessment of RC and URM buildings. Bull Earthq Eng 4:391-413

Lagomarsino S, Giovinazzi S (2006) Macroseismic and mechanical models for the vulnerability assessment of current buildings. Bull Earthq Eng 4(4):415-443

Mwafy AM, Elnashai AS (2002) Calibration of force reduction factors of RC buildings. J Earthq Eng $6(2): 239-273$

NZSEE (2003) Assessment and improvement of the structural performance of buildings in earthquakes (draft). New Zealand Society for Earthquake Engineering, Wellington

O.P.C.M. 3274 (2003) Ordinanza del Presidente del Consiglio dei Ministri n. 3274 del 20/3/2003, Primi elementi in materia di criteri generali per la classificazione sismica del territorio nazionale e di normative tecniche per le costruzioni in zona sismica, G.U. della Repubblica Italiana n.105 dell'8/5/2003 (in Italian)

O.P.C.M. 3431 (2005) Ordinanza del Presidente del Consiglio dei Ministri n. 3431 del 3/5/2005, Ulteriori modifiche ed integrazioni all'ordinanza del Presidente del Consiglio dei Ministri n. 3274 del 20 marzo 2003, G.U. della Repubblica Italiana n.107 (in Italian)

Petruzzelli F, Jalayer F, Iervolino I, Manfredi I (2010) Optimal programming of in-situ tests and inspections for existing buildings. In: Proceedingsof 14th European conference on earthquake engineering, Ohrid, Republic of Macedonia

Petruzzelli F (2013) Scale-dependent procedures for seismic risk assessment and management of industrial building portfolios. Ph.D Thesis, advisor: I. Iervolino. Università degli Studi di Napoli Federico II, Naples, Italy. http://wpage.unina.it/iuniervo/papers/TESI_DOTT_FabioPetruzzelli.pdf

Polese M (2002) Un approccio a Doppio Livello per la valutazione della Vulnerabilità Sismica delle Strutture in C.A. Ph.D Thesis, advisor: G. Manfredi. Università degli Studi di Napoli Federico II, Naples, Italy. http://www.dist.unina.it/doc/tesidott/PhD2002.Polese.pdf (In Italian)

Ricci P, De Luca F, Verderame GM (2011) 6th April 2009 earthquake, Italy: reinforced concrete building performance. Earthq Engn Struct Dyn 40(8):925-944

Rossetto T, Elnashai A (2003) Derivation of vulnerability functions for European-type RC structures based on observational data. Eng Struct 25:1241-1263

Rota M. Penna A. Strobbia C (2008) Processing Italian damage data to derive typological fragility curves. Soil Dyn Earthq Eng 28(10-11):933-947

SERGISAI (1997) First year progress report of the SERGISAI project, European Commission Directorate General XII for Science, Research and Development Environment and Climate 1994-1998

Stucchi M, Meletti C, Montaldo V, Crowley H, Calvi GM, Boschi E (2011) Seismic hazard assessment (2003-2009) for the Italian building code. Bull Seismol Soc Am 101:1885-1911

Publisher's note Springer Nature remains neutral with regard to jurisdictional claims in published maps and institutional affiliations. 